Felipe da Costa Tourinho Teixeira Souza

\title{
Investigação numérica sobre a interação entre modos de flambagem globais e locais em vigas casteladas
}

Dissertação de Mestrado

Dissertação apresentada como requisito parcial para obtenção do grau de Mestre pelo Programa de PósGraduação em Engenharia Civil do Departamento de Engenharia Civil e Ambiental da PUC-Rio.

Orientadora: Prof ${ }^{a}$ Elisa Dominguez Sotelino

Coorientador: Prof. Daniel Carlos Taissum Cardoso

Rio de Janeiro dezembro de 2019 
Felipe da Costa Tourinho Teixeira Souza

Investigação numérica sobre a interação entre modos de flambagem globais e locais em vigas casteladas

Dissertação apresentada como requisito parcial para obtenção do grau de Mestre pelo Programa de PósGraduação em Engenharia Civil da PUC-Rio. Aprovada pela Comissão Examinadora abaixo.

Profa. Elisa Dominguez Sotelino

Orientador

Departamento de Engenharia Civil e Ambiental - PUC-Rio

Prof. Daniel Carlos Taissum Cardoso

Coorientador

Departamento de Engenharia Civil e Ambiental - PUC-Rio

Prof. Raul Rosas e Silva

Departamento de Engenharia Civil e Ambiental - PUC-Rio

Prof. Eduardo de Miranda Batista

UFRJ

Prof. Cássio Marques Rodrigues Gaspar

Departamento de Engenharia Civil e Ambiental - PUC-Rio

Rio de Janeiro, 20 de dezembro de 2019 
Todos os direitos reservados. É proibida a reprodução total ou parcial do trabalho sem autorização da universidade, da autora e do orientador.

\section{Felipe da Costa Tourinho Teixeira Souza}

Graduado em Engenharia Civil pela PUC-Rio (Pontifícia Universidade Católica do Rio de Janeiro) em 2017. Sua área de interesse compreende instabilidade de estruturas, modelagem numérica e estruturas metálicas.

Ficha Catalográfica

\section{Souza, Felipe da Costa Tourinho Teixeira}

Investigação numérica sobre a interação entre modos de flambagem globais e locais em vigas casteladas / Felipe da Costa Tourinho Teixeira Souza ; orientadora: Elisa Dominguez Sotelino ; co-orientador: Daniel Carlos Taissum Cardoso. 2019.

64 f. : il. color. ; $30 \mathrm{~cm}$

Dissertação (mestrado)-Pontifícia Universidade Católica do Rio de Janeiro, Departamento de Engenharia Civil e Ambiental, 2019.

Inclui bibliografia

1. Engenharia Civil e Ambiental - Teses. 2. Interação entre modos de flambagem. 3. Método da resistência direta. 4. Vigas casteladas. 5. Modelagem computacional. 6. Flambagem global. I. Sotelino, Elisa Dominguez. II. Cardoso, 


\section{Agradecimentos}

Primeiramente, gostaria de agradecer meus orientadores Elisa e Daniel, por toda a paciência ao longo do árduo processo de desenvolvimento desta pesquisa. Os incontáveis encontros do grupo de pesquisa foram de fundamental importância no meu crescimento acadêmico, profissional e pessoal.

Aos meus pais, irmãos e familiares, um muito obrigado por todo suporte dado desde o dia que deixei minha cidade natal. Sem o apoio incondicional de vocês, nada disso teria acontecido.

Aos meus grandes amigos da sala 608L, E’ric, Lucian, Chris, Ícaro e Vitor, e de fora dela, Marcello, João e Osmar, que nossa amizade perdure por muito tempo e que nossas longas conversas sejam com o mesmo alto astral de sempre.

Aos colegas do grupo de pesquisa de vigas casteladas, nossas reuniões foram sempre muito produtivas e motivadoras.

Aos examinadores, professores Raul Rosas, Eduardo Batista e Cássio Gaspar, obrigado por aceitarem fazer parte desta banca.

À família Padilha, Gabriela, Huáscar, Martha, Rodrigo e Fernanda, muito obrigado por estarem ao meu lado nos momentos bons e por não pouparem esforços para me ajudar em todos os momentos difíceis ao longo dos últimos anos. Vocês foram fundamentais nesta caminhada.

Ao departamento de Engenharia Civil e Ambiental e a todos os colegas do programa de pós-graduação da PUC-Rio. Os 7 anos que passei nesta universidade, apesar de cansativos, foram incríveis e forjaram minha personalidade acadêmica e profissional.

O presente trabalho foi realizado com apoio da Coordenação de Aperfeiçoamento de Pessoal de Nível Superior - Brasil (CAPES) - Código de Financiamento 001. 


\section{Resumo}

Souza, Felipe da Costa Tourinho Teixeira Souza; Sotelino, Elisa Dominguez; Cardoso, Daniel Carlos Taissum. Investigação numérica sobre a interação entre modos de flambagem globais e locais em vigas casteladas. Rio de Janeiro, 2019. 64p. Dissertação de mestrado - Departamento de Engenharia Civil e Ambiental, Pontifícia Universidade Católica do Rio de Janeiro.

O presente trabalho visa investigar a interação entre a flambagem lateral com torção e a flambagem local do 'tê' comprimido em vigas casteladas. O método dos elementos finitos (MEF) é usado para realizar análises paramétricas de vigas Litzkas sujeitas a flexão pura e considerando combinações da razão entre espessura e comprimento das mesas e alma, além do comprimento destravado. Para considerar a possibilidade de aço com diferentes resistências ao escoamento, esbeltezes adimensionais são utilizadas para prever o comportamento da estrutura de maneira compreensiva. As respostas de vigas com diferentes combinações de esbeltezes são comparadas e a resistência relativa de cada uma delas é discutida. A influência das imperfeições iniciais na capacidade de resistência é avaliada. Os momentos últimos calculados a partir do MEF são comparados com aqueles calculados de acordo com as normas de dimensionamento para vigas casteladas, mostrando que esses podem superestimar ou subestimar as capacidades de resistência. Finalmente, uma abordagem com o método da resistência direta é testada para prever a resistência nominal à flexão. Através das análises feitas, conclui-se que o Design Guide subestima a resistência das geometrias analisadas, o método da resistência direta as superestima e as imperfeições iniciais têm influência no comportamento das vigas analisadas.

\section{Palavras-chave}

Interação entre modos de flambagem; Método da resistência direta; Vigas casteladas; Modelagem computacional; Flambagem global e local. 


\section{Abstract}

Souza, Felipe da Costa Tourinho Teixeira Souza; Sotelino, Elisa Dominguez (Advisor); Cardoso, Daniel Carlos Taissum (Coadvisor). A numerical investigation on the interaction between global and local buckling modes in castellated beams. Rio de Janeiro, 2019. 64p. Dissertação de mestrado Departamento de Engenharia Civil e Ambiental, Pontifícia Universidade Católica do Rio de Janeiro.

The present work aims to investigate the interaction between lateral torsional buckling and compression 'tee' local buckling in castellated beams. The finite element method (FEM) is used to perform a parametric study for Litzka-beams subject to pure bending moment considering combinations of flange-to-web width and thickness ratios and unbraced lengths. To account for the possibility of different yield strengths, non-dimensional local and global slenderness are used to assess the behavior in a comprehensive manner. The responses for beams having different combinations of slendernesses are compared and the relative strengths are discussed. The influence of the initial imperfections on the strength capacity is evaluated. The FEM ultimate bending moments are compared to those calculated according to the current design recommendations for castellated beams, showing that these may either over or underpredict actual capacities. Finally, a direct strength method approach is tested for the prediction of the nominal bending strength. Through the performed analyses it was concluded that the Design Guide underestimate the relative strengths of the analyzed geometries, while the direct strength method overestimated them and the initial imperfections influence the structural behavior of the analyzed beams.

\section{Keywords}

Interaction between buckling modes; Direct Strength Method; Castellated beams; Computational modeling; Global and local buckling. 


\section{Sumário}

1 Introdução 13

1.1. Introdução 13

1.2. Motivação 14

1.3. Objetivos 15

1.4. Escopo 15

1.5. Estrutura do trabalho 16

2 Revisão bibliográfica $\quad 17$

2.1. Acoplamento de modos de flambagem e o método da resistência direta 17

2.2. Design Guide 31

2.3. Esbeltezes e resistência relativa 23

$\begin{array}{ll}2.4 \text {. Vigas casteladas } & 25\end{array}$

3 Modelagem numérica e metodologia de pesquisa 31

3.1. Validação 31

3.2. Modelos de elementos finitos 32

3.3. Análise de elementos finitos 37

3.3.1. Análise linear de flambagem 37

3.3.2. Análise não linear com imperfeição geométrica 38

4 Resultados e discussões $\quad 40$

4.1. Análise linear de flambagem 40

4.2. Análise não linear 41

4.3. Resistência relativa 51

5 Conclusões e sugestões para pesquisas futuras 56

5.1. Conclusões 56 
5.2. Sugestões para pesquisas futuras

6 Referências bibliográficas 


\section{Lista de abreviaturas}

$\begin{array}{ll}\text { AISC } & \text { American Institute of Steel Construction } \\ \text { AISI } & \text { American Iron and Steel Institute } \\ \text { DG } & \text { Design Guide } 31 \\ \text { EM } & \text { Enrugamento da mesa } \\ \text { FLT } & \text { Flambagem lateral com torção } \\ \text { FSM } & \text { Finite Strip Method (Método das Faixas Finitas) } \\ \text { FT } & \text { Flambagem local do 'tê' } \\ \text { GBT } & \text { Generalized Beam Theory (Teoria da Viga Generalizada) } \\ \text { LPF } & \text { Fator de proporcionalidade de momento fletor } \\ M R D & \text { Método da Resistência Direta } \\ P & \text { Plastificação }\end{array}$




\section{Lista de símbolos}

\section{Romanos:}

d Altura do 'tê' comprimido

E Módulo de elasticidade

$F_{y} \quad$ Tensão de escoamento do material

H Altura da seção transversal

ly Momento de inércia em relação ao eixo de menor inércia da seção transversal

\lrcorner$\quad$ Constante torsional da seção transversal

L Comprimento destravado

$L_{b} \quad$ Comprimento destravado

$L_{p} \quad$ Comprimento destravado limite para o estado limite de plastificação

Lr Comprimento destravado limite para o estado limite de flambagem lateral com torção inelástica

Mcre Momento crítico de flambagem global

McrL Momento crítico de flambagem local

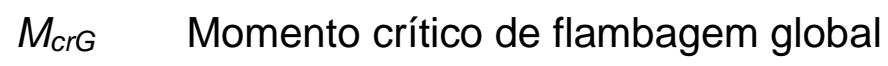

Mne Momento resistente global nominal de Euler

$M_{n L} \quad$ Momento resistente local nominal

$M_{p} \quad$ Momento de plastificação total da seção

$M u_{D G} \quad$ Momento último segundo Design Guide

MUDSM Momento último segundo método da resistência direta 
MUMEF Momento último segundo método dos elementos finitos

My Momento de início de plastificação

ry Raio de giração em torno do eixo y

$S_{x}$

Módulo elástico referente à mesa comprimida, levando em consideração o furo da seção

$S_{x c} \quad$ consideração o furo

\section{Gregos:}

$\varepsilon \quad$ Deformação

$\lambda \quad$ Esbeltez local da mesa

$\lambda_{G} \quad$ Esbeltez global

$\lambda_{L} \quad$ Esbeltez local

$\lambda_{L, D S M} \quad$ Esbeltez local para o método da resistência direta

$\lambda_{p f} \quad$ Limite de esbeltez para mesas compactas

$\lambda_{r f} \quad$ Limite de esbeltez para mesas não-compactas

$\sigma \quad$ Tensão

x Resistência relativa

XMEF Resistência relativa do MEF

XDG Resistência relativa do Design Guide 31

XMRD Resistência relativa do MRD 
"Nothing in life is to be feared, it is only to be understood. Now is the time to understand more, so that we may fear less." 


\section{Introdução}

1.1.

Introdução

Cada vez mais os projetos arquitetônicos demandam à engenharia estrutural vencer longos vãos utilizando elementos estruturais leves e que possam ser bons aliados em termos de funcionalidade e estética, otimizando os espaços e a utilização, principalmente no que se refere às áreas em que há passagem de dutos técnicos. As vigas casteladas se apresentam como uma opção para suprir estas necessidades, visto que perfis laminados são facilmente produzidos e, com isso, aliam geometrias eficientes à qualidade dos aços utilizados atualmente.

Vigas casteladas são aquelas obtidas do corte e expansão da alma de uma viga I de alma cheia e são uma opção para variados tipos de prédio e estruturas como armazéns, ginásios, prédios garagens, hospitais e outros. A Figura 1.1 apresenta uma fotografia de um prédio industrial como exemplo.

Estas vigas apresentam rigidez à flexão e resistências maiores que as vigas I de alma cheia com o mesmo peso, o que quer dizer que a relação entre o peso do elemento e a resistência é maior, resultando em redução do peso final da estrutura e, consequentemente, dos custos relacionados a colunas e fundações. No entanto, como esses elementos surgem da expansão da alma, estes se tornam relativamente mais esbeltos e, estão, então, mais sujeitos a problemas de instabilidade, desenvolvendo alguns estados limites diferentes dos conhecidos nas vigas I tradicionais. 


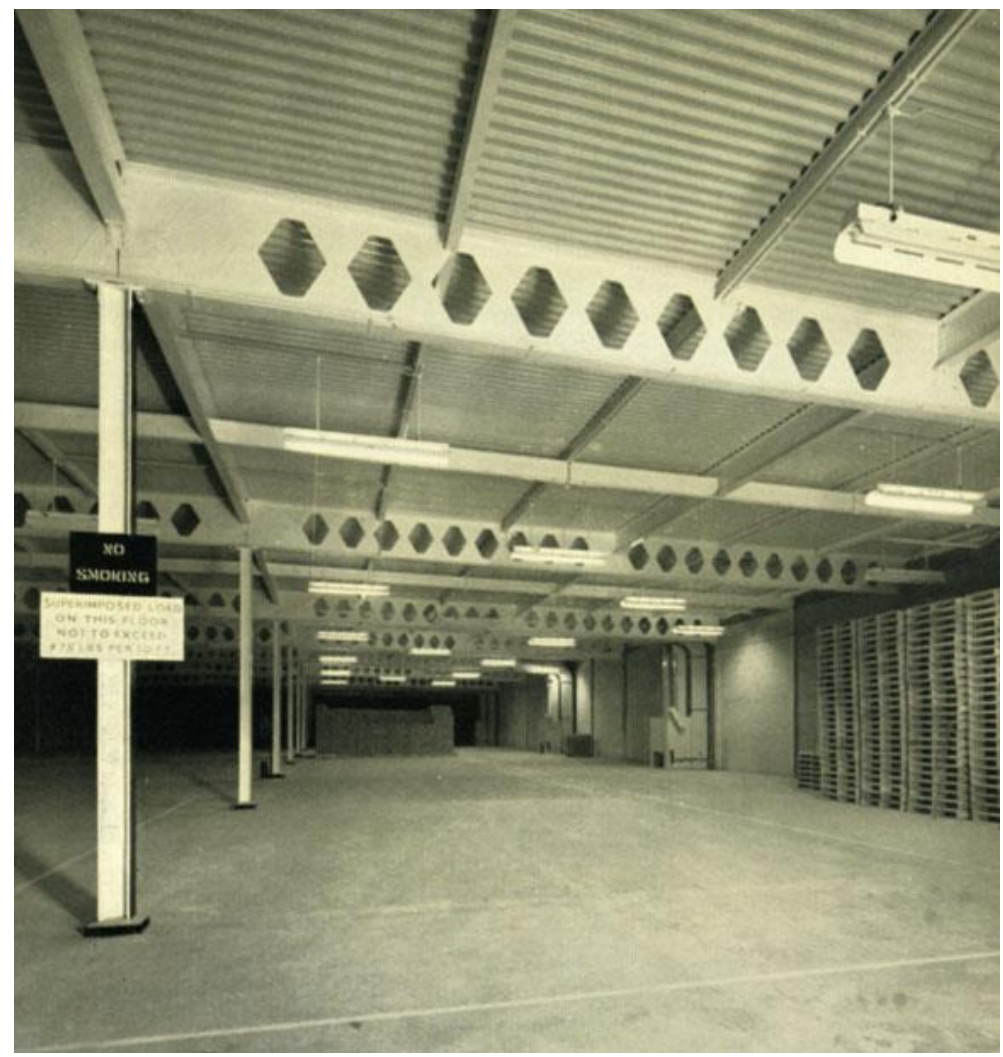

Figura 1.1 - Fábrica da Heinz localizada em Kitt Green, EUA. [1]

\section{2. \\ Motivação}

Os atuais guias de projeto para avaliar os estados-limite últimos de vigas casteladas incluem verificações individuais, além das verificações da viga como um todo, no caso de flambagem lateral com torção, das regiões acima e abaixo das aberturas, denominadas como 'tês', e da porção entres furos, denominadas como web-post, assumindo que a distribuição das forças internas se dá de forma similar às vigas Vierendeel.

Embora exista uma boa quantidade de estudos e publicações científicas acerca do comportamento das vigas casteladas, ainda há casos de carregamentos que os manuais de dimensionamento não deixam claro quanto ao seu comportamento diante destas solicitações e sugerem análises mais complexas, o que demanda um maior custo computacional e menor eficiência no dimensionamento destas estruturas. Ainda no âmbito das lacunas do conhecimento sobre o comportamento que estas peças apresentam, a interação entre os modos de flambagem lateral com torção e a flambagem local dos 'tê' comprimido é pouco compreendida e não há 
estudos recentes que envolvam estes modos de instabilidade de forma conjunta.

1.3.

Objetivos

O objetivo desta pesquisa é analisar o efeito da interação entre os modos de flambagem lateral com torção e flambagem local do 'tê' no comportamento de vigas casteladas. Para isso, um estudo paramétrico utilizando o método dos elementos finitos é desenvolvido e, com base nos resultados, são feitas análises quanto às respostas destes modelos computacionais às solicitações aplicadas.

Os resultados das simulações computacionais são comparados com as previsões de resistência feitas segundo o manual de dimensionamento americano Design Guide 31 [2] e com as expressões presentes no Método da Resistência Direta para perfis formados a frio [3], com a finalidade de avaliar a aplicabilidade dessas duas abordagens quando há a interação entre os modos de flambagem acima citados.

\section{4. \\ Escopo}

Dentro da infinidade de possibilidades de formatos de aberturas, distanciamento entre furos e configurações para vigas casteladas, este trabalho se limita à análise de vigas casteladas biapoiadas, sob flexão pura e de padrão Litzka. Além disto, para o estudo paramétrico são observadas 5 diferentes imperfeições iniciais e é utilizado modelo constitutivo elástico perfeitamente plástico, desconsiderando o encruamento do material, e sem influência de tensões residuais.

O Método da Resistência Direta (MRD) [3] é utilizado para perfis formados a frio e sem furos. Apesar das vigas casteladas serem perfis laminados e possuírem furos, a abordagem do MRD é empregada devido à consideração da interação entre os modos de flambagem no cálculo da resistência dos elementos estruturais. 


\section{5.}

\section{Estrutura do trabalho}

Este trabalho de pesquisa está divido em 5 capítulos, organizados da seguinte forma:

O capítulo 2 apresenta uma revisão de conceitos importantes para o desenvolvimento da pesquisa e relaciona os tópicos estudados a trabalhos científicos já publicados.

O capítulo 3 descreve os modelos numéricos, os tipos de elementos finitos utilizados, as condições de contorno, o estudo de convergência da malha escolhida, a aplicação do carregamento e a validação das técnicas de modelagem.

O capítulo 4 expõe os resultados do estudo com gráficos, tabelas e comparações de resistência entre os métodos de cálculo empregados.

O capítulo 5 apresenta as conclusões e sugestões para pesquisas futuras acerca do tema exposto. 


\section{2 Revisão bibliográfica}

Este capítulo apresenta conceitos e estudos acerca dos assuntos mais importantes para o entendimento do desenvolvimento deste trabalho. Estudos relacionados ao acoplamento de modos de flambagem e ao emprego do método da resistência direta são descritos. Discute-se brevemente a abordagem que o guia de dimensionamento americano (Design Guide 31 [2]) adota para as vigas casteladas e celulares. Os conceitos de esbeltez global e local são apresentados. Por último, são expostos trabalhos acerca dos modos de falha já estudos em vigas casteladas.

\section{1.}

\section{Acoplamento de modos de flambagem e o método da resistência direta}

Os primeiros estudos a citar o acoplamento de modos de flambagem datam de 1945 e foram elaborados por Koiter [4], que desenvolveu a teoria moderna de estabilidade estrutural de sistemas elásticos contínuos, e posteriormente continuado por Budiansky [5]. Em seguida, Thompson [6] utilizou coordenadas generalizadas para o desenvolvimento da teoria geral para sistemas discretos.

O desenvolvimento da teoria moderna teve grande avanço quando Chilver [7] publicou um trabalho avaliando as consequências de cargas críticas iguais, ou bem próximas, para sistemas de 2 graus de liberdade, mostrando, então, que o sistema possui outras configurações deformadas, além das configurações dos modos independentes.

Desenvolvimentos importantes nessa linha foram feitos por Johns [8, 9, 10], Johns \& Chilver [11], Supple [12, 13, 14], Ho [15, 16], Thompson \& Gaspar [17] e Thompson \& Hunt [18], levando em consideração caminhos 
pós-críticos com e sem acoplamento de modos de flambagem, além da sensibilidade de sistemas às imperfeições iniciais.

No que tange o desenvolvimento dos estudos que consideram a interação de modos de flambagem, Bijlaard e Fisher [19, 20] foram os primeiros a investigar a interação de modos de flambagem local e global, comparando valores teóricos com resultados experimentais para seções transversais quadradas de alumínio. Van der Neut [21,22] investigou a sensibilidade às imperfeições iniciais para estes casos e concluiu que a perda da capacidade de resistência devido ao acoplamento de modos de flambagem, somado a existência de imperfeições iniciais, é importante para colunas simétricas de paredes finas.

Grande parte das pesquisas desenvolvidas nos anos seguintes empregou o conceito da espessura efetiva para considerar flambagem local e gerar seções efetivas, i.e., considerando propriedades reduzidas para o cálculo da resistência à flambagem global.

O Método da Resistência Direta (MRD) foi inicialmente mencionado e proposto para vigas de perfis formados a frio por Schafer e Pekoz [23]. Esta metodologia se baseia na estabilidade elástica dos membros, de modo que, com os carregamentos críticos bem determinados, a resistência do elemento estrutural pode ser determinada. Além das cargas de flambagem elástica, o MRD também demanda o cálculo da carga de plastificação da seção para previsão da capacidade. A resistência final é uma função de parâmetros de esbeltez computados através da relação entre cargas de plastificação e cargas críticas.

Deve-se notar que a correlação entre cargas de falha com razão de flambagem não foi uma ideia proposta inicialmente por Schafer e Pekoz [23]. Esta ideia de correlação foi apresentada em um estudo de colunas sob flambagem distorcional desenvolvido por Hancock et al. [24] e também em pesquisa conduzida por Trahair [25] onde se determinou curvas de resistência para flambagem devido à flexo-torção.

Desde o início o MRD engloba membros com carregamentos combinados, cisalhamento e torção, como mostra Schafer [26, 27] e Bian et al. [28]. Avanços no método levam em consideração interação entre modos de flambagem, corrugação da alma e membros sob elevadas 
temperaturas, como mostram Camotim et al. [29] e Landesmann et al. [30]. A versão mais recente do MRD publicada no AISI [31] foi desenvolvida para membros sob ações de carregamento axial e momentos combinados. Resumos dos avanços do MRD podem ser encontrados nos estudos de Camotim et al. [32] e Torabian \& Schafer [33].

O Método da Resistência Direta moderno [34], presente na norma americana para dimensionamento de estruturas de aço de perfis formados a frio AISI NAS S100 [3], é empregado para obter a resistência de membros de almas cheias sob compressão ou flexão pura, considerando a interação entre modos de flambagem. Na verdade, o conceito fundamental que se baseia o MRD consiste no fato de que a resistência do elemento estrutural pode ser diretamente determinada em função da carga crítica elástica para diferentes modos de flambagem (i.e. global, local e distorcional) e da tensão de escoamento. No presente trabalho, o foco está no procedimento recomendado pelo código do AISI [35] para analisar vigas somente sob interação entre flambagem global e local. A abordagem do MRD não é aplicável a perfis laminados com aberturas, mas a atual pesquisa avalia como é o comportamento do método para membros castelados.

Para utilizar as equações do MRD, a fim de determinar a resistência das vigas, é necessário determinar previamente os respectivos momentos críticos de cada modo de flambagem, que podem ser obtidos utilizando o método das faixas finitas (Finite Strip Method - FSM), método dos elementos finitos (MEF), teoria da viga generalizada (Generalized Beam Theory - GBT) ou usando soluções teóricas de flambagem elástica disponíveis na literatura. Para o caso específico de vigas casteladas, o MEF mostra-se mais apropriado, uma vez que permite a introdução de descontinuidades como furos e aberturas ao longo do comprimento do membro, além de ser possível introduzir variadas condições de contorno. É importante mencionar que o método não é calibrado para os perfis laminados, logo, o importante para a avaliação das interações é a abordagem do método e não a calibração.

O primeiro passo do método é determinar o momento nominal global, que diz respeito à flambagem global, $M_{n e}$, utilizando as Eq. (1), (2) e (3), que correlacionam o momento crítico de flambagem global, $M_{c r e}$, e o 
momento de início de plastificação, $M_{y}$, onde a razão $M_{y}$ sobre $M_{c r e}$ está relacionada à esbeltez global:

$$
\begin{array}{rc}
\text { Se } M_{\text {cre }}<0.56 M_{y} & M_{\text {ne }}=M_{\text {cre }} \\
\text { Se } 2.78 M_{y} \geq M_{\text {cre }} \geq 0.56 M_{y} & M_{n e}=\frac{10}{9} M_{y}\left(1-\frac{10 M_{y}}{36 M_{\text {cre }}}\right) \\
\text { Se } M_{\text {cre }}>2.78 M_{y} & M_{n e}=M_{y}
\end{array}
$$

Então, o momento resistente local nominal, que leva em consideração a interação modal, $M_{n L}$, deve ser calculado utilizando a Eq. (4), (5) e (6). Estas equações correlacionam o momento global nominal do passo anterior e o momento crítico local, $M_{c r L}$, como segue:

$$
\lambda_{L, D S M}=\sqrt{\frac{M_{n e}}{M_{c r L}}}
$$

Se $\lambda_{L, D S M} \leq$

$$
M_{n L}=M_{n e}
$$

$$
\begin{array}{r}
\text { Se } \lambda_{L, D S M}> \\
0.766
\end{array} \quad M_{n L}=M_{n e}\left(1-0.15\left(\frac{M_{c r L}}{M_{n e}}\right)^{0.4}\right)\left(\frac{M_{c r L}}{M_{n e}}\right)^{0.4}
$$

Onde $\lambda_{L, D S M}$ é a esbeltez local para o MRD e $M_{c r L}$ é o momento crítico de flambagem local.

\section{2.}

\section{Design Guide 31}

O AISC Design Guide 31 - Castellated and Cellular beam design (DG) [2] é um documento recentemente publicado pelo Instituto Americano de Construção em Aço (American Institute of Steel Construction - AISC) que provê as diretrizes práticas para o dimensionamento de vigas casteladas nos Estados Unidos. O manual prático está conforme o documento 2016 AISC Specifications [36] e cobre os mecanismos de falha que diferem dos mecanismos presentes em vigas de alma cheia, como o mecanismo Vierendeel, flambagem do web-post e flambagem do tê comprimido (FT). Para os propósitos desta pesquisa, os momentos últimos são calculados para FT e para flambagem lateral com torção (FLT). É importante destacar que o Design Guide apresenta seções para cálculo do momento de FT e 
do FLT separadamente, no entanto, não há menção sobre a interação entre modos de flambagem.

O cálculo do momento resistente nominal à flambagem lateral com torção, $M_{n}$, é direcionado na seção $F 9.2$ e as formulações para o dimensionamento seguem da Eq. (7) à Eq. (12). Vale ressaltar que o método utilizado para o dimensionamento leva em consideração a plastificação total da seção transversal. Quando $L_{b} \leq L_{p}$, o estado limite de FLT não se aplica.

Quando $L_{p}<L_{b}<L_{r}$

$$
M_{n}=M_{p}-\left(M_{p}-M_{y}\right)\left(\frac{L_{b}-L_{p}}{L_{r}-L_{p}}\right)
$$

Quando $L_{b}>L_{r}$

$$
M_{n}=M_{c r}
$$

Onde

$$
\begin{gathered}
L_{p}=1.76 r_{y} \sqrt{\frac{E}{F_{y}}} \\
L_{p}=1.95\left(\frac{E}{F_{y}}\right) \frac{\sqrt{I_{y} J}}{S_{x}} \sqrt{2.36\left(\frac{F_{y}}{E}\right) \frac{d S_{x}}{J}+1} \\
M_{c r}=\frac{1.95 E}{L_{b}} \sqrt{I_{y} J}\left(B+\sqrt{1+B^{2}}\right) \\
B=-2.3\left(\frac{d}{L_{b}}\right) \sqrt{\frac{I_{y}}{J}}
\end{gathered}
$$

Onde:

$M_{y}$ é o momento do início da plastificação da seção transversal;

$M_{p}$ é o momento de plastificação total da seção transversal;

$L_{b}$ é o comprimento destravado do membro;

$L_{p}$ é o comprimento destravado limite para o estado limite de plastificação;

$L_{r}$ é o comprimento destravado limite para o estado limite de flambagem lateral com torção inelástica; 


$$
L_{r}=1.95 * \sqrt{\frac{\sqrt{I_{y} C_{w}}}{S_{x}}} *\left(\frac{E}{0.7 F_{y}}\right) * \sqrt{\frac{J c}{S_{x} h_{0}}+\sqrt{\left(\frac{J c}{S_{x} h_{0}}\right)^{2}+6.76\left(\frac{0.7 F_{y}}{E}\right)^{2}}}
$$

$r_{y}$ é o raio de giração em torno do eixo y;

$C_{w}$ é a constante de empenamento da seção transversal;

E é o módulo de elasticidade do material;

$F_{y}$ é a tensão de escoamento do material;

$l_{y}$ é o momento de inércia em relação ao eixo de menor inércia da seção transversal;

$J$ é a constante torsional da seção transversal;

$S_{x}$ é o módulo elástico referente à mesa comprimida, levando em consideração o furo da seção;

$d$ é a altura do 'tê' comprimido.

O cálculo do momento resistente nominal local da mesa comprimida é direcionado na seção F9.3 e as formulações para o dimensionamento seguem da Eq. (13) à Eq. (14). Para seções com mesas compactas sob compressão, o estado limite de flambagem da mesa não se aplica.

Para seções com mesa não-compacta em compressão:

$$
\begin{gathered}
M_{n}=\left[M_{p}-\left(M_{p}-0.7 F_{y} S_{x c}\right)\left(\frac{\lambda-\lambda_{p f}}{\lambda_{r f}-\lambda_{p f}}\right)\right] \\
\leq 1.6 M_{y}
\end{gathered}
$$

Para seções com mesa esbelta em compressão:

$$
M_{n}=\frac{0.7 E S_{x c}}{\left(\frac{b_{f}}{2 t_{f}}\right)^{2}}
$$

Onde:

$S_{x c}$ é o módulo elástico referente à mesa comprimida, levando em consideração o furo.

$\lambda=\frac{b_{f}}{2 t_{f}}$

$\lambda_{p f}=\lambda_{p}$, limite de esbeltez para mesas compactas, AISC Specification tabela B4.1b (vide anexo A).

$\lambda_{r f}=\lambda_{r}$, limite de esbeltez para mesas não-compactas, AISC Specification tabela B4.1b (vide anexo A). 


\section{3.}

\section{Esbeltezes e resistência relativa}

Neste trabalho, são adotadas esbeltezes global e local, as quais são definidas como a raiz quadrada da razão entre o momento de início de plastificação $\left(M_{y}\right)$ e o respectivo momento crítico, tanto para esbeltez global como local, $\lambda=\sqrt{\frac{M_{y}}{M_{c r}}}$. Esta definição é baseada em como a esbeltez relativa é considerada para vigas sujeitas a flambagem global, como mostra Može [37] e, desta forma, os parâmetros necessários para obter a esbeltez são apenas o momento de início de plastificação e o momento crítico, não sendo necessário emprego dos parâmetros geométricos das vigas diretamente.

A curva típica de resistência para vigas perfeitas está na Figura 2.1, onde o eixo horizontal representa a esbeltez e o vertical a resistência relativa, que para compressão pura é a razão entre carga última e carga de plastificação e para flexão pura, é a razão entre o momento último e o momento de plastificação total da seção, $\chi=\frac{M_{u}}{M_{p}}$. Uma vez que os momentos de início da plastificação e o momento de plastificação total para seção transversal I, principalmente com furos, são próximos, pode-se realizar a aproximação de $M_{p}=M_{y}$. Considerando elementos perfeitos compactos $(\lambda<1)$, o modo de falha corresponde à plastificação completa da seção transversal. Por outro lado, os membros perfeitos esbeltos $(\lambda>1)$ têm suas capacidades governadas por instabilidade. 


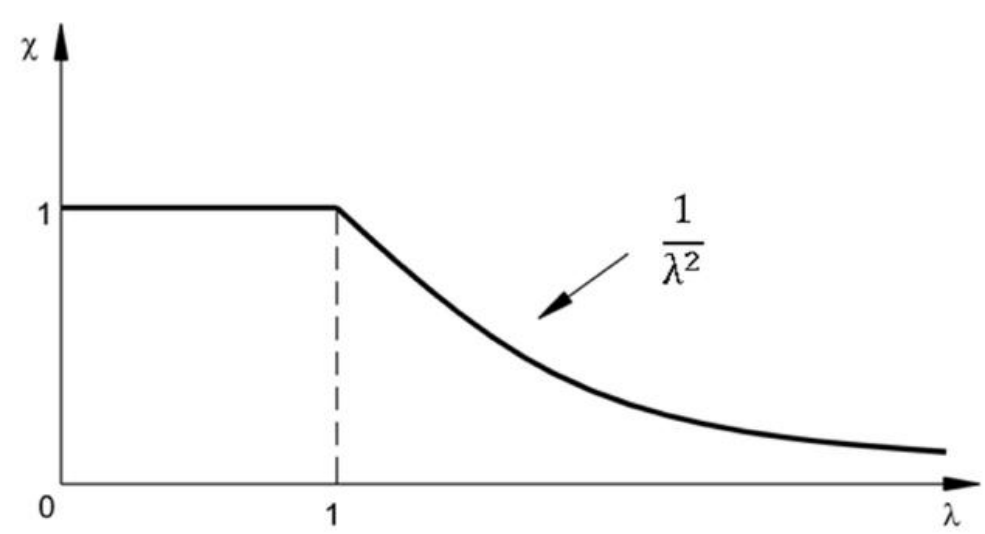

Figura 2.1 - Curva de resistência para estruturas sem imperfeições, bi apoiada e com material elástico perfeitamente plástico

Quando imperfeições são consideradas, a curva de resistência e as capacidades de carga tendem a diminuir para elementos com comportamento similar ao de colunas. O comportamento dessa curva para estruturas com imperfeições está ilustrado na Figura 2.2 e mostra de forma esquemática a influência das imperfeições em elementos não-compactos e esbeltos.

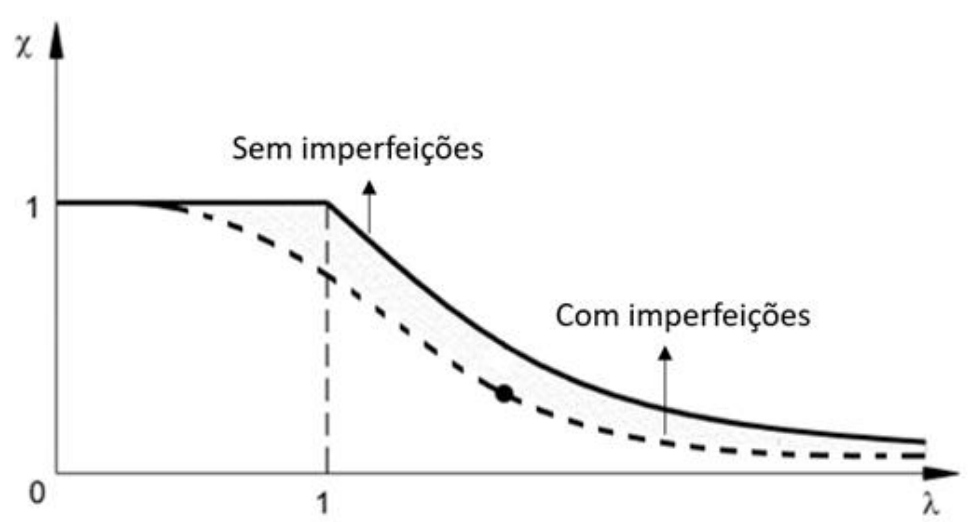

Figura 2.2 - Curva de resistência de vigas ideais, em linha cheia, e não ideais, em linha pontilhada.

Em contrapartida, elementos de placas finas apresentam comportamento oposto, como ilustrado na Figura 2.3. A redistribuição de tensões para as regiões rígidas faz com que a placa apresente ganho de resistência pós-flambagem.

Na presença de imperfeições, a região próxima à interseção da curva de flambagem e o limite plástico mostra a maior redução de capacidade de 
resistência com respeito ao comportamento perfeito, devido a interação entre modos de falha. Em função da reserva de resistência pós-crítica, elementos que apresentam comportamento de placas finas podem apresentar capacidade de resistência superior à resistência crítica.

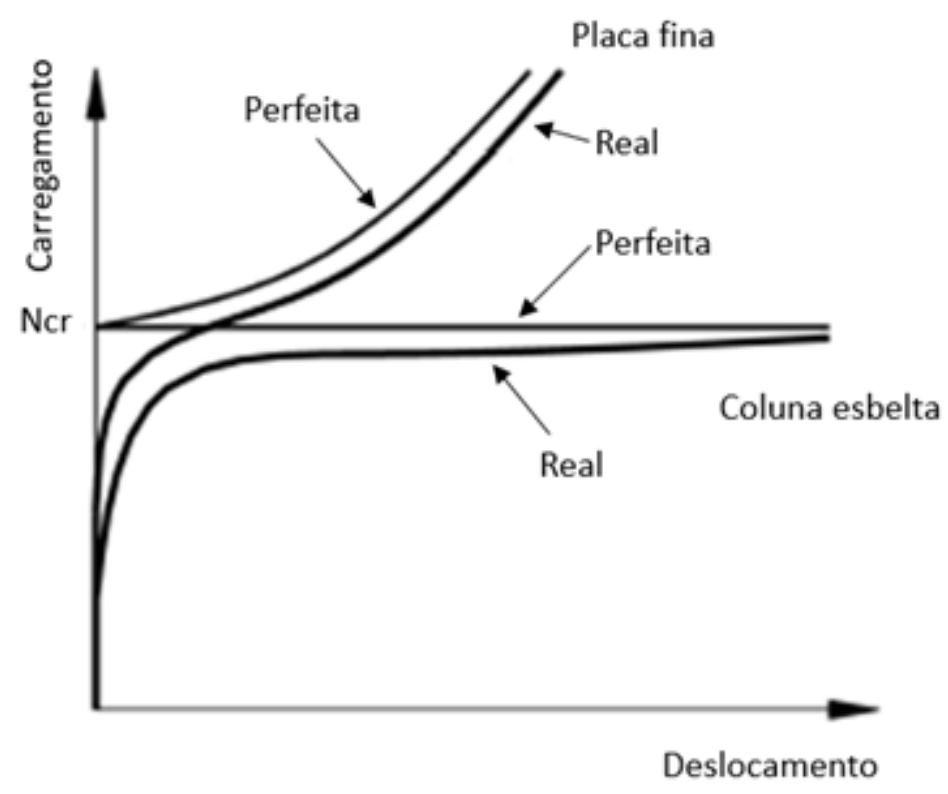

Figura 2.3 - Comportamento de colunas esbeltas e placas finas

\section{4 .}

Vigas casteladas

O processo de fabricação de vigas casteladas é caracterizado pelo corte da alma ao longo do comprimento em formato de zigue-zague, criando assim o formato desejado após a separação das metades da viga e a soldagem. Este processo resulta em uma perda de aço, uma vez que as extremidades excedentes são retiradas após o fim do processo, como mostra a Figura 2.4. O padrão de corte é diferente para cada viga resultante, como as casteladas, celulares e Angelinas [38]. 


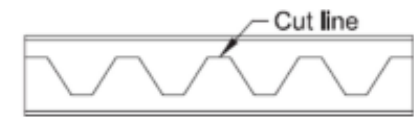

(a)

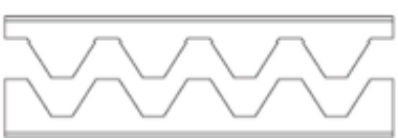

(b)

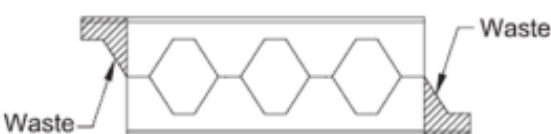

(c)

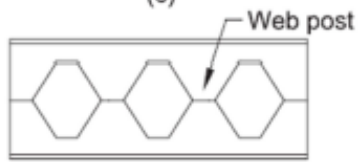

(d)

Figura 2.4 - Processo de fabricação viga castelada [2]

A viga castelada comumente utilizada é a Litzka-Schnittfürung [39], também conhecida como Litzka, e, por essa razão, é a selecionada para o desenvolvimento desta pesquisa. A razão entre a altura total da viga, $d$, e a altura do furo, que é a altura da viga original (antes do processo de fabricação da viga castelada), $d_{h}$, deve ser 1,5 e a distância entre o centro de furos consecutivos, $S$, deve ser igual a altura total da viga e o ângulo do hexágono é tal que a tangente do ângulo é igual a 2. A Figura 2.5 mostra a relação entre os parâmetros.

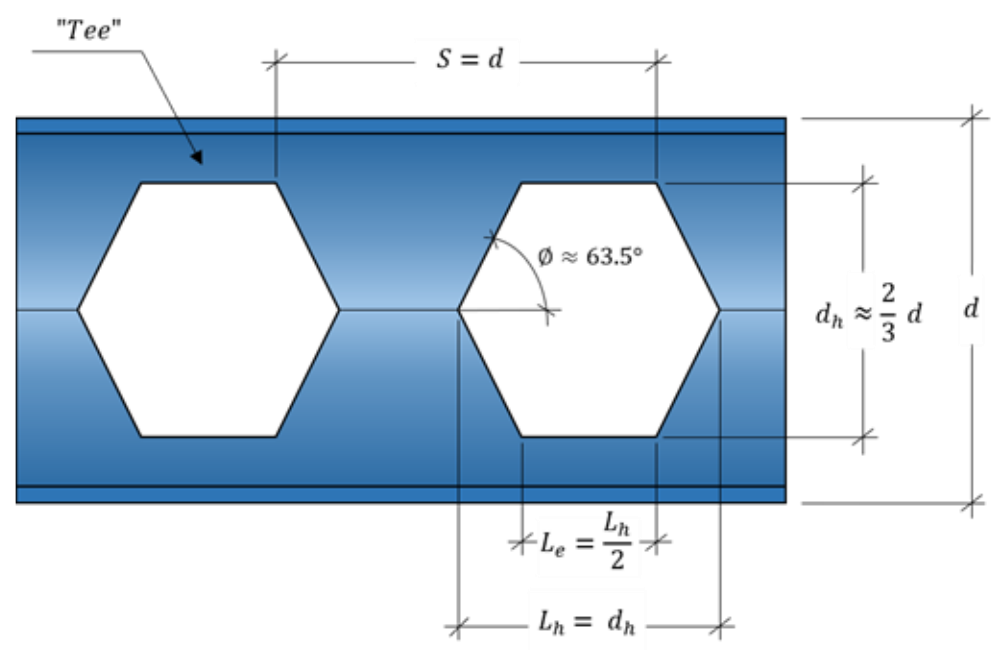

Figura 2.5 - Parâmetros das vigas tipo Litzka

Boyer [40] constatou que vigas casteladas se comportam e devem ser analisadas como vigas Vierendeel. Além disso, desenvolveu critérios de dimensionamento e procedimentos, a fim de considerar os modos de falha das vigas casteladas que diferem de vigas de alma cheia.

Kerdal \& Nethercot [41] concluíram que os códigos de dimensionamento adotados a época costumavam subestimar a resistência 
das vigas casteladas em torno de $40 \%$ e que ser ultraconservador é o preço a se pagar devido à natureza complexa do dimensionamento desses elementos estruturais. Kerdal e Nethercot [42] conduziram grande número de experimentos para avaliar as resistências últimas destes elementos e concluíram que a flambagem lateral aconteceu em todos os espécimes, de modo que um travamento lateral adequado é necessário para avaliação dos demais modos de falha individualmente. Desta forma, encontraram que são 6 os modos de falha de uma viga castelada:

1. Formação do mecanismo Vierendeel

2. Flambagem à flexo-torção do web-post

3. Ruptura da solda

4. Flambagem à flexo-torção do vão inteiro

5. Flambagem do web-post

6. Formação do mecanismo de flexão

Investigações experimentais e numéricas foram realizadas nas últimas duas décadas, a fim de estudar a resistência de vigas casteladas e vigas celulares. Zaarour \& Redwood [43] realizaram testes experimentais em 14 vigas para avaliar a importância da consideração da flambagem do web-post nos dimensionamentos e concluíram que é imprescindível a consideração deste modo de falha. Redwood \& Demirdjian [44] fizeram análises elásticas por elementos finitos, além de testes experimentais, de 4 vigas casteladas sob condição de flexão em três pontos e com a mesa superior lateralmente restringida, a fim de evitar flambagem fora do plano, e avaliaram a resistência do web-post, além da influência da relação momento-esforço cortante na resistência e carga crítica.

Chung et al. [45] estudaram a ocorrência do mecanismo de Vierendeel em vigas com aberturas de formato quadrado, retangular, circular, circular alongado e hexagonal, como mostra a Figura 2.6. Observaram o padrão de plastificação nos tês abaixo e acima dos furos, exceto para os furos circulares e circular alongado. Foi concluído que o mecanismo de Vierendeel é de suma importância para avaliar a resistência da seção. Redwood e Cho [46] sugeriram que o comportamento de vigas com aberturas nas almas é governado pelas deformações de Vierendeel, resultantes da combinação do cisalhamento e do momento fletor e que a 
flambagem local da mesa possui pouca influência na resistência última destes membros. Tais afirmações explicam a pouca atenção cedida ao fenômeno de flambagem local do 'tê' em vigas casteladas. Rasmussen \& Hancock [47] estudaram e mostraram que aços de resistências elevadas modificam a esbeltez limite das placas constituintes, aumentando a possibilidade do modo de flambagem local acontecer antes da plastificação do 'tê'.

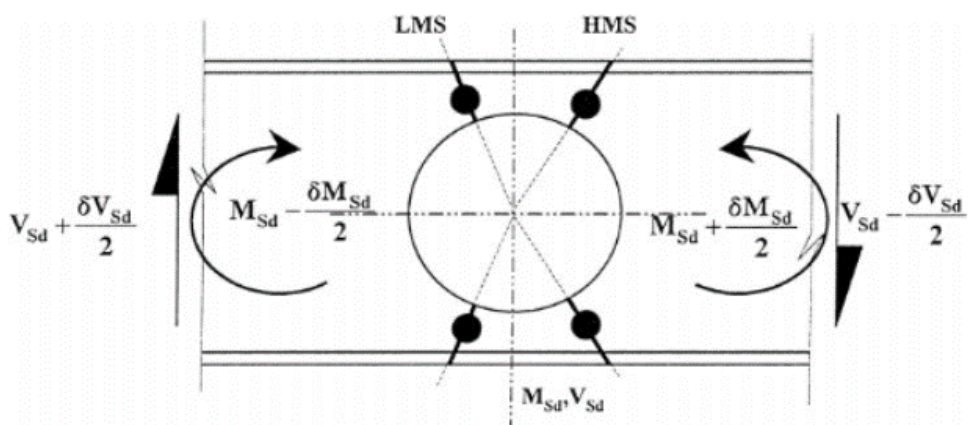

Figura 2.6 - Ilustração esforços globais em vigas celulares, Chung et al. [45]

Sweedan [48] investigou numericamente a flambagem lateral de vigas celulares de paredes finas biapoiadas sob diversas condições de carregamento e considerando diferentes tamanhos de furos, vãos e parâmetros de seção transversal. Sonck [49] estudou a flambagem global, com configuração conforme Figura 2.7, em vigas e colunas celulares e casteladas, com escopo considerando apenas momentos constantes ou compressão simples, elementos com aberturas regulares, duplamente simétricos, biapoiados e considerando somente os eixos de menor inércia. Além dos já mencionados, diversos outros estudos foram realizados acerca da flambagem lateral com torção de vigas celulares, como Panedpojaman et al. [50], Boissonnade et al.[51], Sonck \& Belis [52] e Taras \& Greiner [53], que estudaram as resistências últimas de vigas celulares sujeitas à flambagem lateral. 


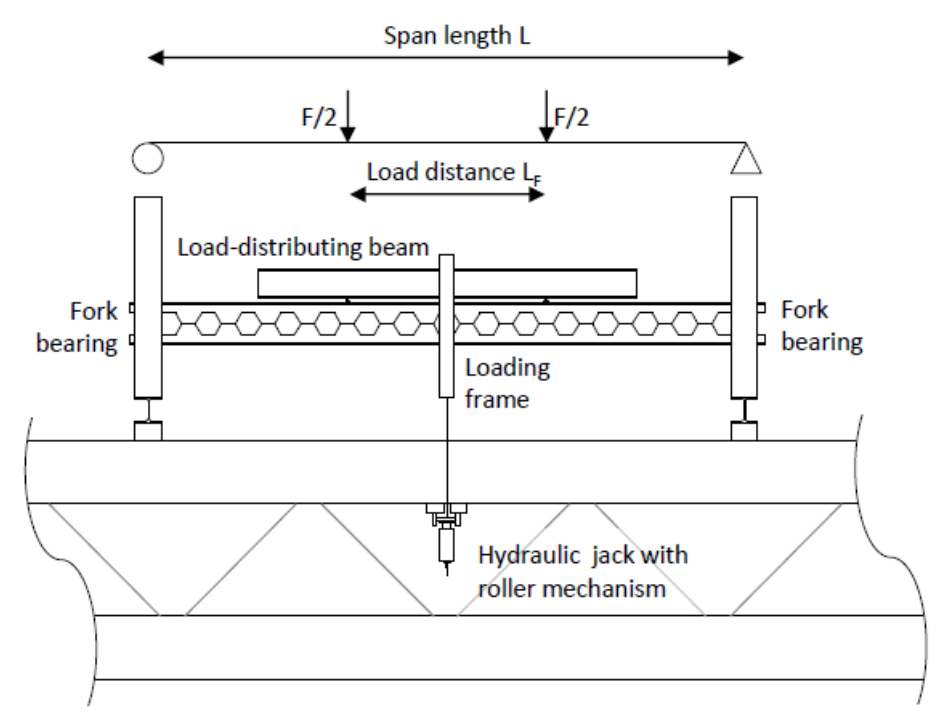

Figura 2.7 - Configuração de ensaio adotada por Sonck [48].

Kerdal \& Nethercot [54] avaliaram as diferenças entre modos de falha de vigas casteladas e vigas de alma cheia. Segundo estes autores, sob condição de flexão pura, as vigas casteladas estão sujeitas a falhar por flambagem lateral com torção ou por formação do mecanismo de flexão, quando tais vigas forem restringidas lateralmente. A possibilidade de flambagem local do 'tê' não é mencionada por tais autores.

Soltani et al. [55] conduziu um estudo paramétrico de análises não lineares com base no MEF que evidenciou que a flambagem local do tê comprimido limitou a capacidade de vigas casteladas. De Oliveira [56] desenvolveu um estudo, a partir de modelos numéricos de elementos finitos, para obter equações explícitas para a estimar a tensão crítica de flambagem elástica local para vigas casteladas sujeitas a flexão pura, considerando interação entre mesa e alma. Este estudo concluiu que a flambagem do 'tê' é relevante para vigas casteladas que utilizam aços de alta resistência. A Figura 2.8 ilustra o modo de flambagem local do 'tê'. 


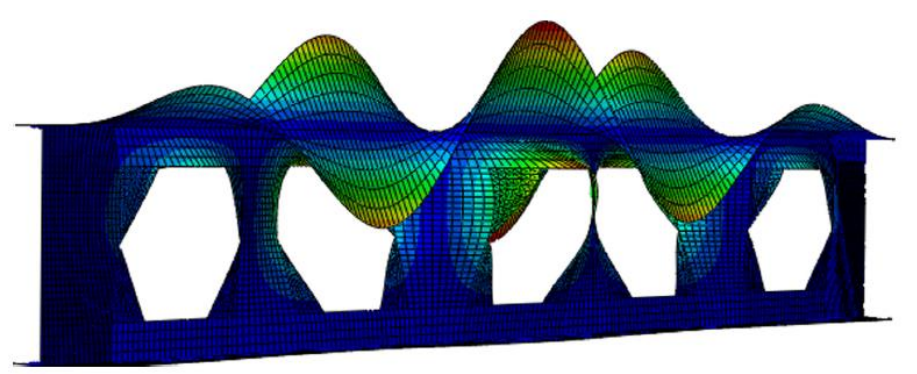

Figura 2.8 - Modo de flambagem típico obtido das análises de autovalor, de Oliveira [56]

Ellobody [57] investigou o comportamento de vigas casteladas utilizando aços normais e de alta resistência com acoplamento de modos lateral com torção e distorcional, como ilustra a Figura 2.9. Este estudo considerou a influência das imperfeições geométricas iniciais e a não linearidade do material. Finalmente, concluiu que os manuais de dimensionamento são conservadores para vigas falhando por flambagem lateral com torção e contra a segurança para vigas falhando por flambagem distorcional. Ellobody [58], em outro estudo, avaliou a resistência de vigas celulares sob modos de flambagem combinados, a partir de estudo paramétrico levando em consideração imperfeições iniciais, não linearidade do material utilizado e tensões residuais. Ele concluiu que vigas celulares que tiveram flambagem distorcional da alma e flambagem do web-post combinadas, apresentaram um decréscimo considerável nas respectivas cargas últimas.

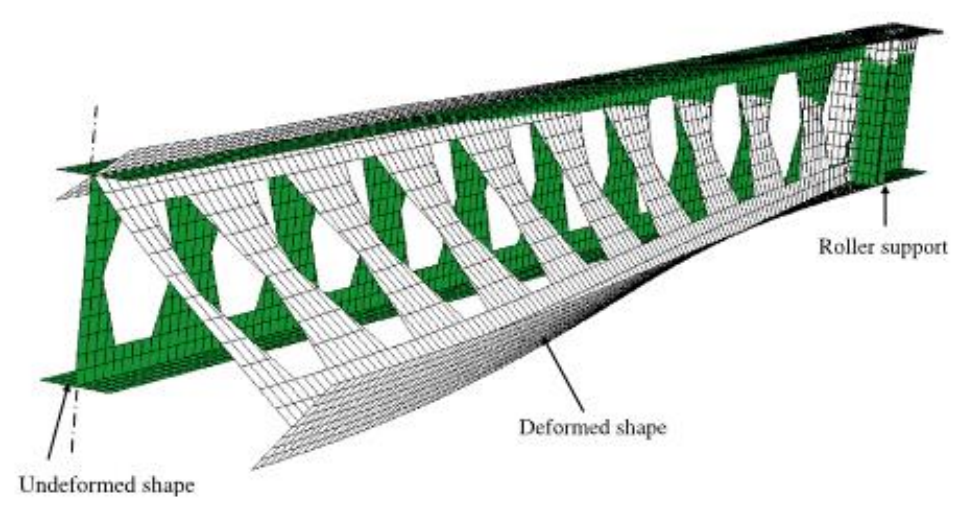

Figura 2.9 - Modo de flambagem lateral distorcional com a mesa superior lateralmente contida, Ellobody [57] 


\section{3 \\ Modelagem numérica e metodologia de pesquisa}

Os modelos de elementos finitos necessários para avaliar os tópicos abordados neste trabalho estão descritos nas seções deste capítulo. Os modelos foram implementados utilizando o software comercial ABAQUS [59]. Este software possibilita a utilização da interface de script, que utiliza a linguagem de programação Python para criar e modificar parâmetros nos modelos, tal como geometria, características de materiais, condições de contorno, carregamentos e tipos de análises, otimizando a utilização da interface gráfica para estudos paramétricos, que demandam muitas alterações nos modelos.

\section{1.}

\section{Validação}

As técnicas de modelagem empregadas neste trabalho foram validadas por comparação da carga crítica e modo de flambagem de um estudo conduzido por Redwood \& Demirdjian [44], cuja configuração é representada na Figura 3.1. Eles avaliaram de forma numérica e de forma experimental o comportamento de vigas casteladas sob condição de flexão em três pontos. O espécime 10-7 do estudo foi selecionado para comparação.

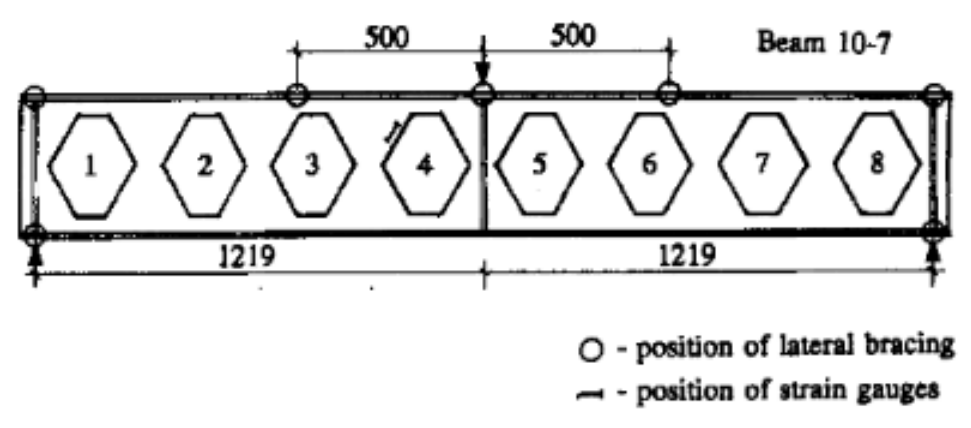

Figura 3.1 - Configuração ensaio de flexão em três pontos [44] 
Neste estudo, o material utilizado possui módulo de elasticidade $\mathrm{E}=$ $200 \mathrm{GPa}$, o peso próprio não é levado em consideração, os apoios utilizados em ambas as extremidades são de primeiro gênero e cinco pontos foram restringidos lateralmente para evitar flambagem lateral. A carga crítica do experimento foi obtida utilizando a técnica de Southwell plot e está descrita na Tabela 3.1, tal como a carga crítica do modelo de elementos finitos, obtida através de uma análise de flambagem linear. Portanto, pode-se notar que a diferença entre a carga crítica obtida no experimento e a modelada neste trabalho é de $1.2 \%$, enquanto a diferença em relação ao modelo de elementos finitos é de $12.8 \%$. Deste modo, então, o modelo numérico é considerado adequado para análises posteriores utilizando as técnicas de modelagem empregadas.

Tabela 3.1 - Resultados de validação

\begin{tabular}{ccc}
\hline Modelo & Carga crítica $(\mathrm{kN})$ & $\begin{array}{c}\text { Diferença } \\
\text { relativa }(\%)\end{array}$ \\
\hline $\begin{array}{c}\text { Experimento } \\
\text { (Redwood \& }\end{array}$ & 91.7 & - \\
Demirdjian [43]) & & \\
Modelagem & & 12.8 \\
$\quad$ (Redwood \& & 81.3 & \\
$\begin{array}{c}\text { Demirdjian [43]) } \\
\text { Modelagem presente } \\
\text { trabalho }\end{array}$ & 92.8 & 1.2 \\
\hline
\end{tabular}

\section{2.}

\section{Modelos de elementos finitos}

Foram utilizados elementos de casca para modelar as vigas do estudo paramétrico. Este elemento é tipicamente utilizado para simular estruturas em que uma das dimensões, neste caso a espessura, é significantemente menor que as demais, o que é o caso dos componentes das vigas casteladas - alma e mesa. 
Com o propósito de obter soluções convergentes utilizando menor número de elementos, optou-se pela utilização de elementos finitos quadráticos. Um dos elementos adotados na simulação numérica foi o S8R5, que é um elemento de casca fina com 8 nós, com integração reduzida e 5 graus de liberdade por nó. 0 elemento quadrático de 8 nós com 5 graus de liberdade por nó foi empregado em toda a viga, com exceção dos entornos dos furos das vigas, onde foi utilizado o elemento STRI65, elemento triangular de 6 nós, com integração reduzida e 5 graus de liberdade por nó, para fazer uma transição suave na malha entre as quinas dos furos e o resto do elemento estrutural. A malha utilizada no estudo, tal como os elementos utilizados, aparece na Figura 3.2.

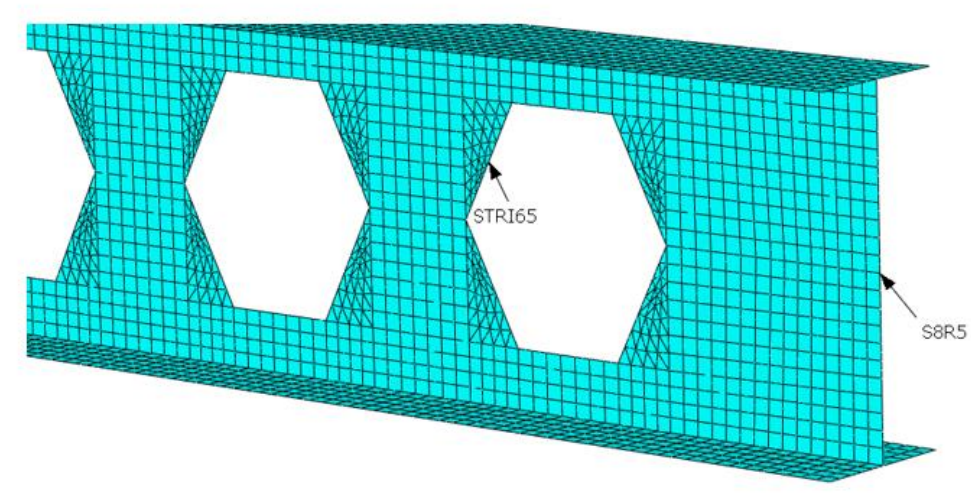

Figura 3.2 - Elementos finitos utilizados

Para a simular a condição de momento uniforme, um momento concentrado é aplicado nas duas extremidades, na altura do centroide da seção transversal. A fim de garantir que as seções planas permaneçam planas e que o momento uniforme seja corretamente distribuído ao longo da seção, a técnica de multi-point constraint, a qual determina que os graus de liberdade dos nós escravos sejam numericamente iguais aos graus de liberdade do nó mestre, foi empregada a todos os nós dos extremos das vigas, conforme Figura 3.3. 


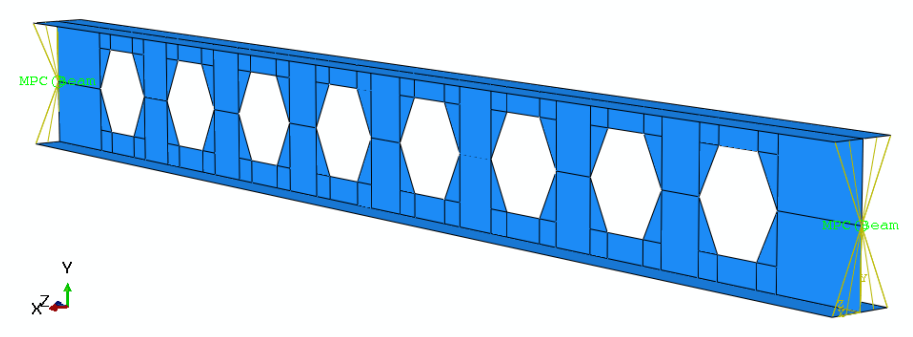

Figura 3.3 - Multi-point constraint nas extremidades da viga

As condições de contorno empregadas definem como a estrutura se comporta e todos os modelos utilizados no estudo paramétrico têm as mesmas condições de contorno. Com o objetivo de simular vigas simplesmente apoiadas, foram adotados suportes nodais no centroide das seções transversais das extremidades e, para isso, os deslocamentos verticais, deslocamentos fora do plano (direções dos eixos " $X$ " e " $Y$ ") e as rotações ao longo dos eixos " $Y$ " e " $Z$ " foram restringidos, além disso, a rotação em torno do eixo " $X$ " foi liberada em ambas extremidades. Adicionalmente, o deslocamento longitudinal de uma das extremidades foi restringido (direção "Z"). As condições de contorno são expostas na Figura 3.4 .

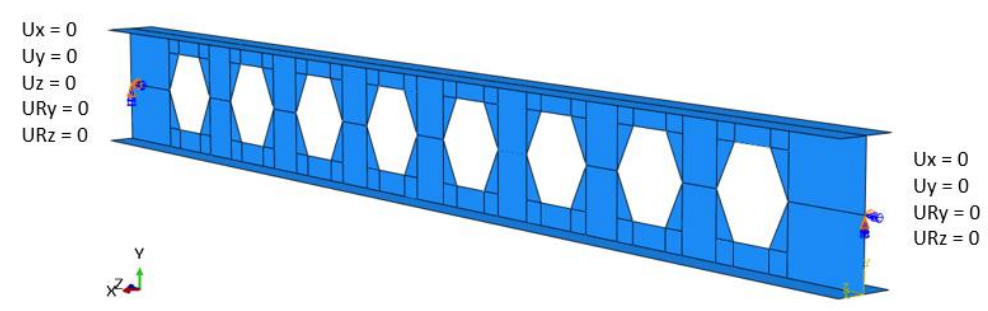

Figura 3.4 - Condições de contorno dos modelos do estudo paramétrico

A definição da densidade da malha de elementos finitos utilizada foi feita com a realização do estudo de convergência. Neste estudo, quatro análises de vigas casteladas sob aplicação de momentos uniformes, biapoiadas e com a técnica de multi-point constraint nas seções transversais das extremidades, são consideradas. Análises lineares de flambagem foram feitas a fim de avaliar a variação do momento fletor crítico e do número de graus de liberdade (GDL), como expõe a Figura 3.5. 


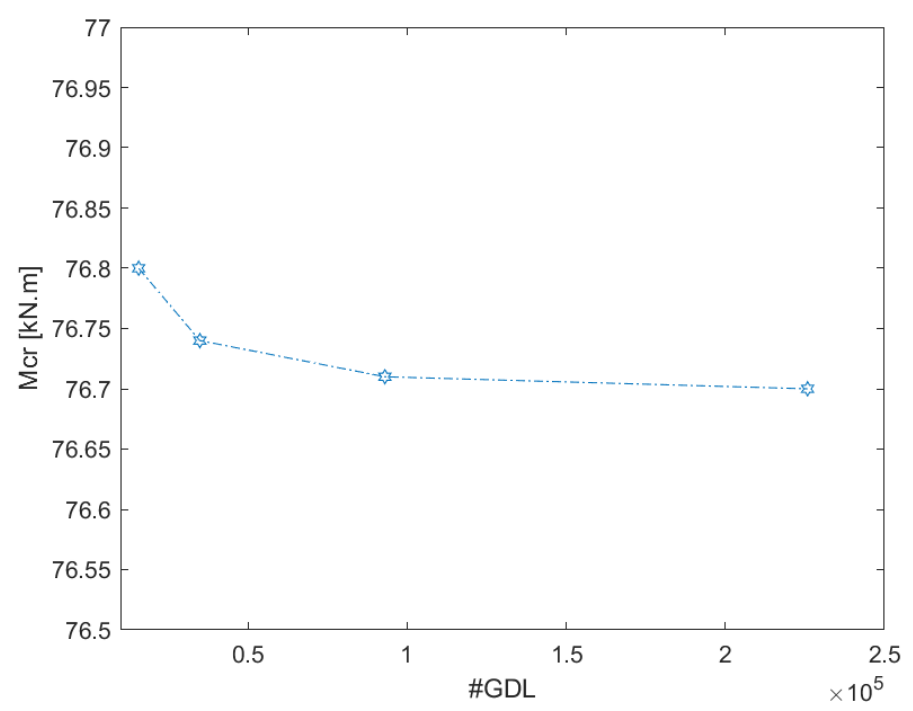

Figura 3.5 - Estudo de convergência para definição de densidade da malha de elementos finitos

Resultados satisfatórios são obtidos a partir de malhas com menos GDL, no entanto, essas malhas apresentam elementos distorcidos, o que poderia prejudicar as soluções buscadas, uma vez que análises de flambagem local são realizadas neste estudo e, por este motivo, a densidade de malha escolhida foi a que tem aproximadamente 225 mil GDL (a mais refinada da Figura 3.5), cujos elementos têm aproximadamente $10 \mathrm{~mm}$ de lado, e apresenta elementos regulares e bem definidos, como mostrado na Figura 3.6.

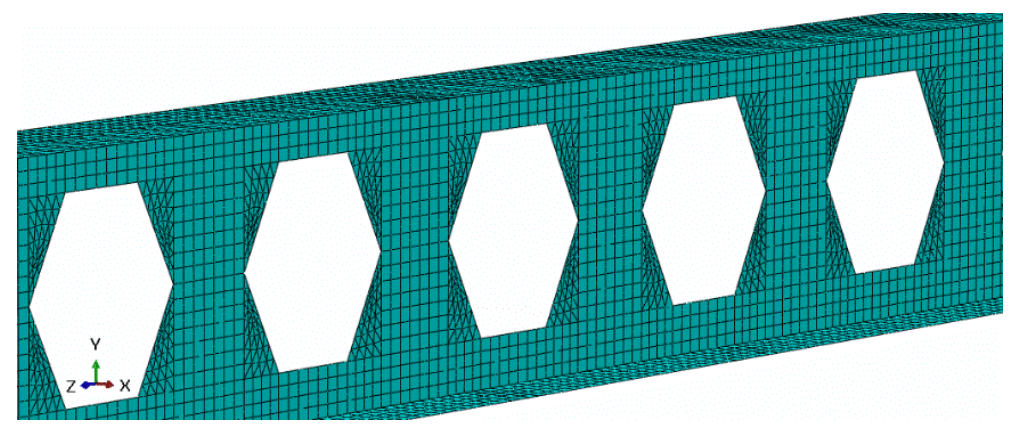

Figura 3.6 - Densidade da malha de elementos finitos selecionada

Estudos preliminares a partir de perfil I castelado presente em catálogos comerciais foram feitos a fim de identificar o comprimento destravado utilizado nesta pesquisa. Com base no vão escolhido, foram feitos estudos para obtenção das espessuras das mesas empregadas no 
estudo paramétrico, com o intuito de se obter a interação entre os modos de flambagem global e local. Os modelos presentes neste estudo paramétrico diferem entre si em relação a comprimento destravado e espessura das mesas, possuindo mesma altura total da viga (h), $222 \mathrm{~mm}$, espessura de alma (tw), 4,3 mm, e comprimento da mesa (bf), $100 \mathrm{~mm}$, dispostos na Figura 3.7 e conforme descritos na Tabela 3.2.

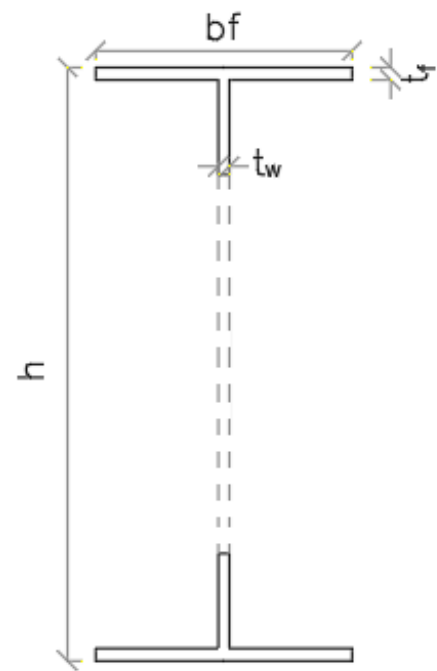

Figura 3.7 - Parâmetros da seção transversal adotada.

Tabela 3.2 - Parâmetros geométricos para o estudo paramétrico

\begin{tabular}{ccc}
\hline Modelo & $\begin{array}{c}\text { Comprimento } \\
\text { destravado } \\
(\mathrm{mm})\end{array}$ & $\begin{array}{c}\text { Espessura da } \\
\text { mesa }(\mathrm{mm})\end{array}$ \\
\hline 1 & 2444 & 4.90 \\
2 & 3110 & 4.90 \\
3 & 3110 & 4.30 \\
4 & 3110 & 3.75 \\
5 & 3110 & 3.35 \\
6 & 3110 & 2.65 \\
7 & 4000 & 4.90
\end{tabular}




\section{3.}

\section{Análise de elementos finitos}

Para a análise da capacidade de resistência das vigas casteladas sob momento uniforme e interação de modos de flambagem, parâmetros como esbeltez global, esbeltez local, referentes ao modo de flambagem global, $\lambda \mathrm{G}$, e ao modo de flambagem local, $\lambda\llcorner$, e a capacidade de resistência relativa referente ao método dos elementos finitos, XMEF, são buscados, além das cargas críticas referentes aos modos de flambagem global e local. Para a obtenção destes parâmetros é necessário a realização de dois tipos de análise: análise linear de flambagem e análise não linear completa (material elasto-plástico e imperfeição geométrica).

\subsection{1.}

\section{Análise linear de flambagem}

Análises de autovalor foram realizadas a fim de obter as cargas críticas e seus respectivos modos de flambagem para as vigas estudadas. Conhecer os carregamentos críticos é necessário para um melhor entendimento do comportamento e para definição dos parâmetros de esbeltez global e esbeltez local, ambas utilizadas na avaliação dos resultados deste estudo. Os modos de flambagem também são utilizados posteriormente para geração das imperfeições iniciais utilizadas nas análises não-lineares.

Ao analisar cada viga, é possível observar como os momentos críticos variam de acordo com a mudança do comprimento destravado, mostrando a relevância deste para o comportamento da estrutura. A Figura 3.8 apresenta os modos típicos de flambagem obtidos das análises de flambagem, que são utilizados para gerar as imperfeições iniciais na análise não-linear. 


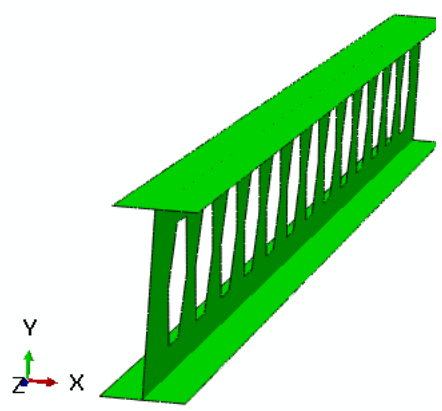

(a)

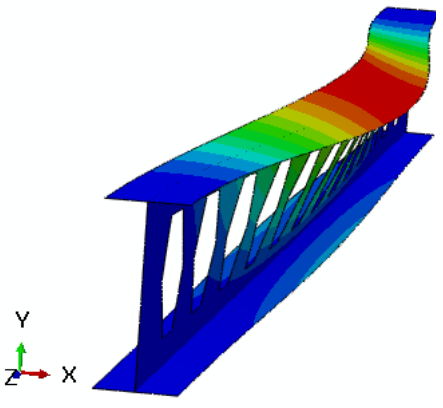

(b)

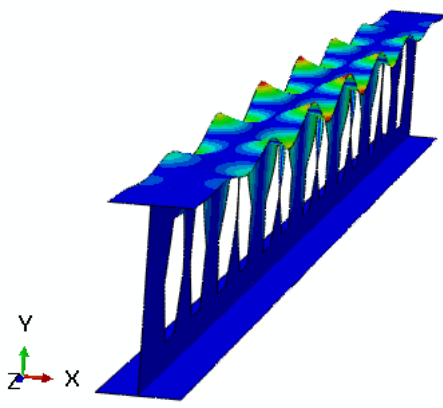

(c)

Figura 3.8 - Modos de flambagens típicos das análises de autovalor: (a) Estrutura indeformada; (b) modo de flambagem por FLT; (c) modo de flambagem local por FT.

\subsection{2.}

\section{Análise não linear com imperfeição geométrica}

As análises não-lineares realizadas nesta pesquisa consideraram o modelo constitutivo elástico-perfeitamente plástico, como mostra o gráfico tensão por deformação presente na Figura 3.9, desconsiderando o encruamento, onde $f_{y}$ é a tensão de escoamento do aço empregado. $O$ método de cálculo para a resposta não-linear da estrutura utilizado foi o método de Riks modificado, com tamanho de incrementos adaptativos, neste caso com tamanho de comprimento de arco variando entre $1 \times 10^{-15} \mathrm{e}$ 0.05, e número de incrementos suficientes para capturar a carga última resistente e a resposta da razão carga por deslocamento pré e pósflambagem. Utilizando 100 incrementos foi possível obter o comportamento de todos os casos estudados. Foram considerados aços com diferentes resistências para as vigas submetidas a análises, variando a tensão de escoamento como sendo 345 ou $690 \mathrm{MPa}$, coeficiente de Poisson igual a 0,3 e módulo de elasticidade $200 \mathrm{GPa}$. 


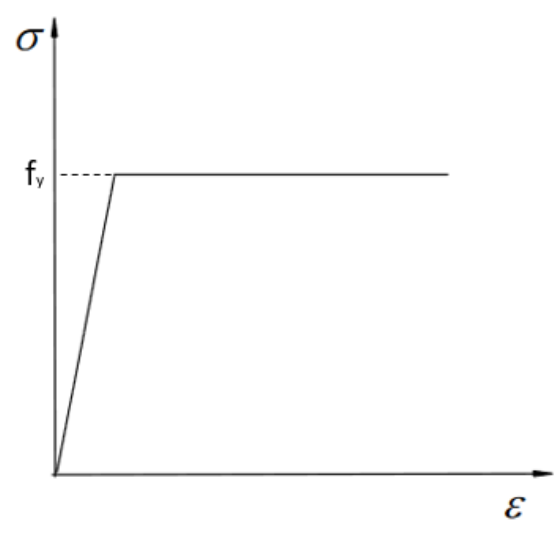

Figura 3.9 - Modelo constitutivo elástico-perfeitamente plástico adotado

Os carregamentos aplicados nas análises não-lineares são iguais às cargas críticas obtidas das análises de flambagem linear. Tensões residuais não foram consideradas no escopo desta pesquisa. As formas das imperfeições iniciais aplicadas a cada modelo são obtidas dos respectivos modos de flambagem extraídos das análises lineares de flambagem e estes são multiplicados por um fator de imperfeição que, no caso, relaciona o comprimento do vão destravado $(L)$ e a altura da seção transversal $(H)$, como mostra a Tabela 3.3. Os fatores de imperfeição local empregados neste estudo foram variações daquele utilizado por Linhares [60], que considerou $H / 500$. Já os fatores de imperfeição global empregados partiram do valor utilizado por Sonck [49], igual a L/1000.

Tabela 3.3 - Tabela de imperfeições iniciais

\begin{tabular}{ccc}
\hline Código & Imperfeição global & Imperfeição local \\
& & \\
\hline IMP 1 & $\mathrm{L} / 1500$ & $\mathrm{H} / 750$ \\
IMP 2 & $\mathrm{L} / 1000$ & $\mathrm{H} / 500$ \\
IMP 3 & $\mathrm{L} / 1000$ & $\mathrm{H} / 250$ \\
IMP 4 & $\mathrm{L} / 750$ & $\mathrm{H} / 500$ \\
IMP 5 & $\mathrm{L} / 750$ & $\mathrm{H} / 250$ \\
\hline
\end{tabular}




\section{Resultados e discussões}

Este capítulo apresenta os resultados obtidos através das análises dos modelos de elementos finitos para cada geometria presente neste trabalho. Além disso, apresenta os valores obtidos conforme o dimensionamento previsto pelo Design Guide 31 [2] e, também, do dimensionamento considerando o Método da Resistência Direta.

\section{1.}

\section{Análise linear de flambagem}

A Figura 4.2, que mostra, ainda, as condições de contorno utilizadas tal que as rotações, com exceção da rotação em torno do eixo foram do plano, e deslocamentos das seções transversais extremas do sistema sejam restringidas.

Tabela 4.1 contém os dados de momentos críticos e momentos de início de plastificação para cada um dos modelos avaliados. Com exceção do modelo 6 , onde o primeiro modo de flambagem mostra que há a flambagem lateral com torção e flambagem local da mesa acontecendo simultaneamente, como na Figura 4.1, em todos os modelos analisados é possível obter modos globais e locais distintos, como exemplifica a Figura 4.2, que mostra, ainda, as condições de contorno utilizadas tal que as rotações, com exceção da rotação em torno do eixo foram do plano, e deslocamentos das seções transversais extremas do sistema sejam restringidas.

Tabela 4.1 - Momentos críticos globais, locais e de início de plastificação.

\begin{tabular}{cccc}
\hline Modelo & $M_{c r_{G}}(\mathrm{kN} . \mathrm{m})$ & $M_{c r_{L}}(\mathrm{kN} . \mathrm{m})$ & $M_{y}(\mathrm{kN} . \mathrm{m})$ \\
\hline 1 & 121.0 & 132.0 & 85.9 \\
2 & 76.7 & 132.0 & 85.9 \\
3 & 67.0 & 101.7 & 77.1
\end{tabular}




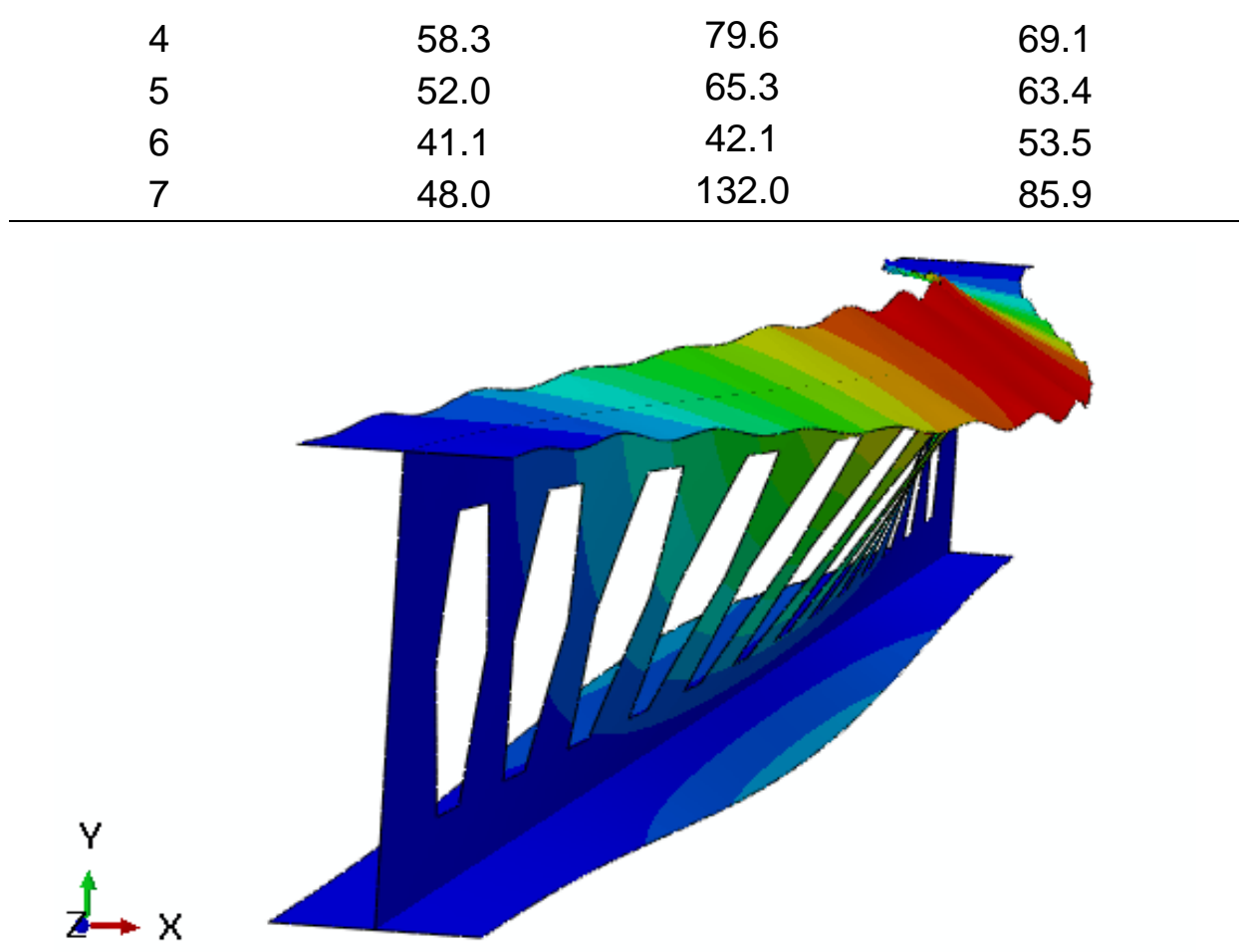

Figura 4.1 - 1ํ modo de flambagem do modelo 6, interação local-global.

(a)

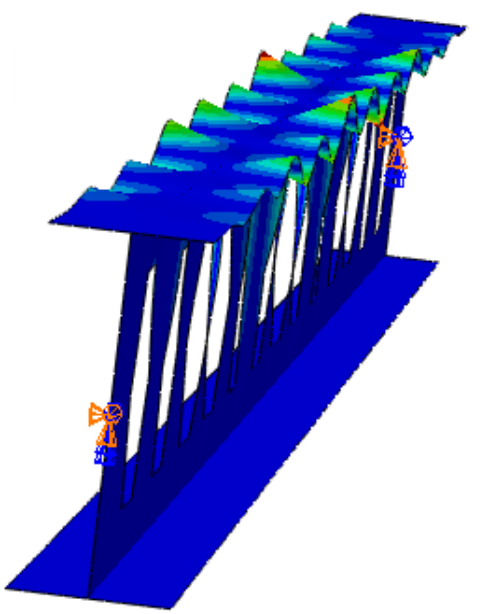

(b)

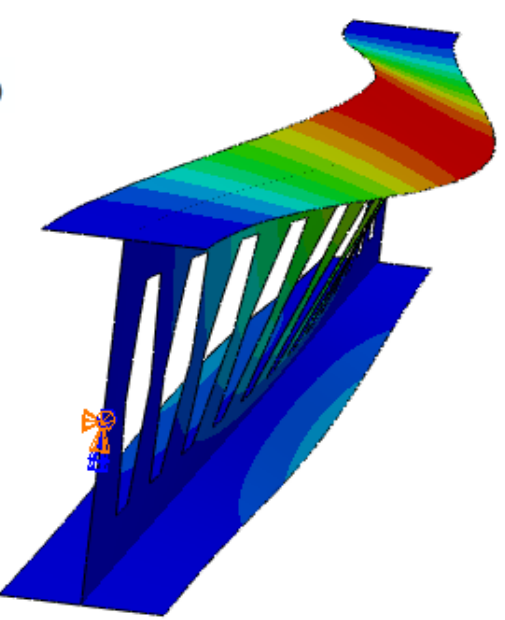

Figura 4.2 - Modos de flambagem distintos do modelo 4: (a) Primeiro modo de flambagem local; (b) Primeiro modo de flambagem global.

\section{2.}

\section{Análise não linear}

As análises não lineares realizadas contêm não linearidade física (do material) e geométrica e, a partir dessas imperfeições, obtém-se as curvas de carga-deslocamento que mostram o comportamento quando há a 
plastificação do material, flambagem global, local ou interação entre os modos de falha.

Para cada modelo foram analisados os comportamentos com os diferentes fatores de imperfeição geométrica citados na seção 3.3.2, para que fosse possível notar como as imperfeições locais e globais influenciam os modos de falha, no que diz respeito ao momento último e o comportamento pós-crítico de cada geometria. A Figura 4.3 apresenta as curvas relacionando o fator de proporcionalidade do momento fletor (LPF) com deslocamento fora do plano no ponto médio da mesa superior, que é o deslocamento horizontal do ponto em vermelho da seção transversal, para as diferentes imperfeições geométricas iniciais consideradas.

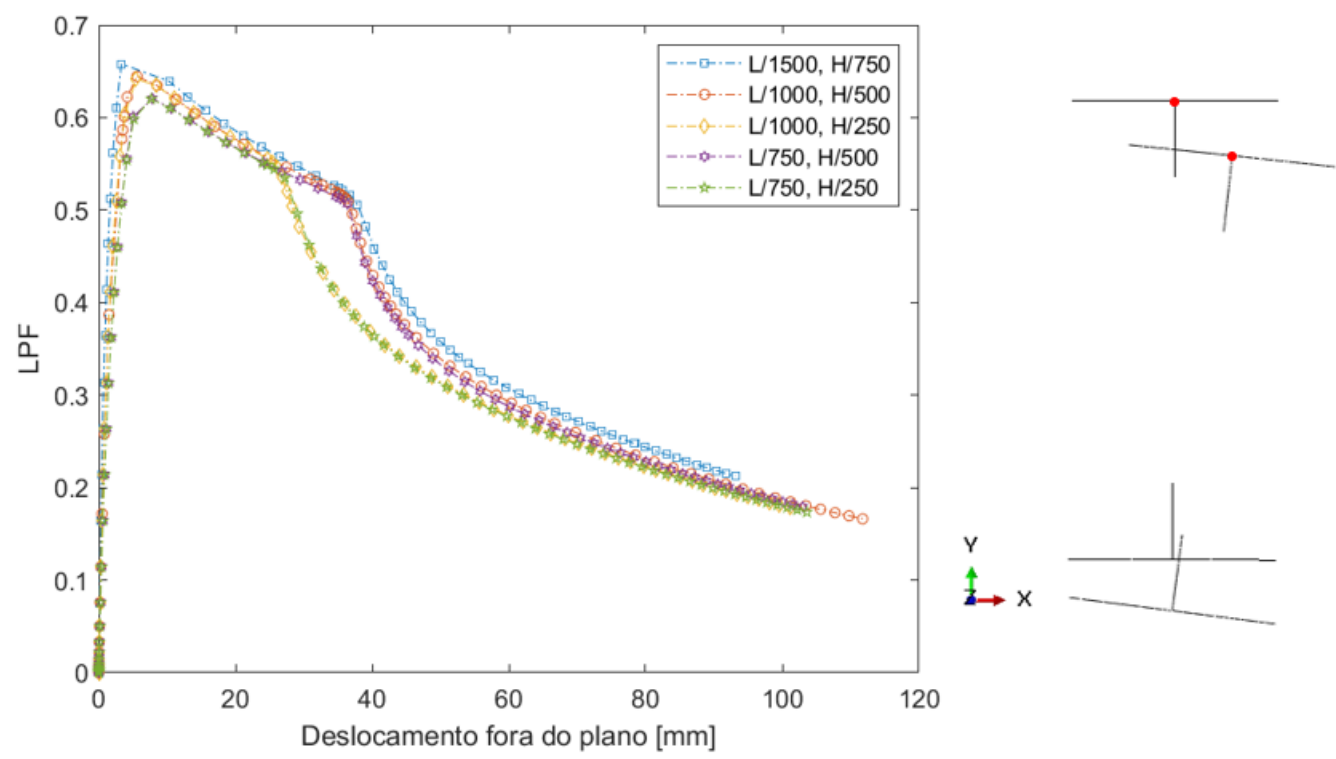

Figura 4.3 - Curva de fator de proporcionalidade do momento fletor (LPF) de momento fletor por deslocamento fora do plano, direção X, do modelo 1.

O modelo 1 tem 0 momento de início de plastificação consideravelmente menor que os momentos críticos local e global, o que pode ser notado com as curvas para as diferentes imperfeições iniciais (Figura 4.3), que apresentam um trecho linear bem definido e, ao iniciar a plastificação da fibra mais externa da seção transversal, que acontece de forma localizada devido às imperfeições, há uma perda de rigidez que leva a flambagem lateral com torção e, em seguida, acontece um enrugamento localizado na mesa comprimida, como é possível observar na Figura 4.4, 
onde (a) mostra os pontos notáveis do gráfico para a geometria testada; (b) é o momento que inicia a plastificação localizada na mesa comprimida; (c) apresenta o início da flambagem lateral com torção; (d) o enrugamento da mesa comprimida. De tal modo, a evolução do modo de falha do modelo 1 é caracterizado pelo início da plastificação, seguido da flambagem lateral com torção e, por fim, o enrugamento da mesa superior.

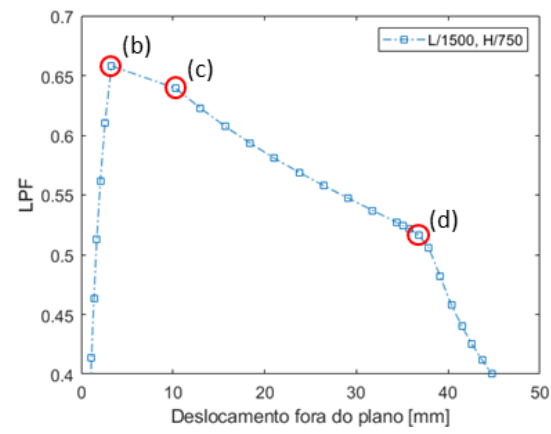

(a)

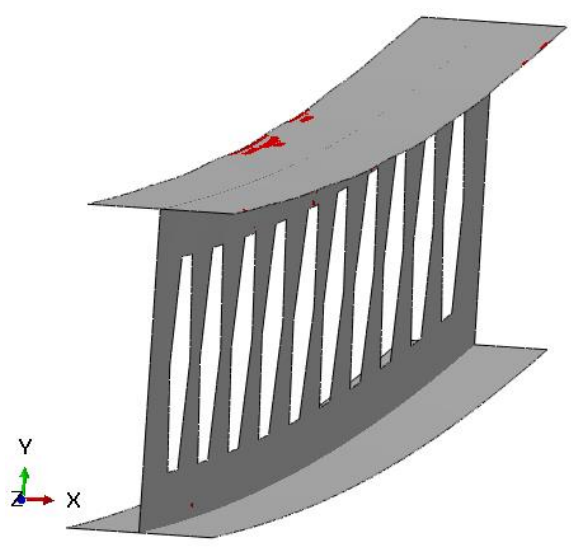

(b)

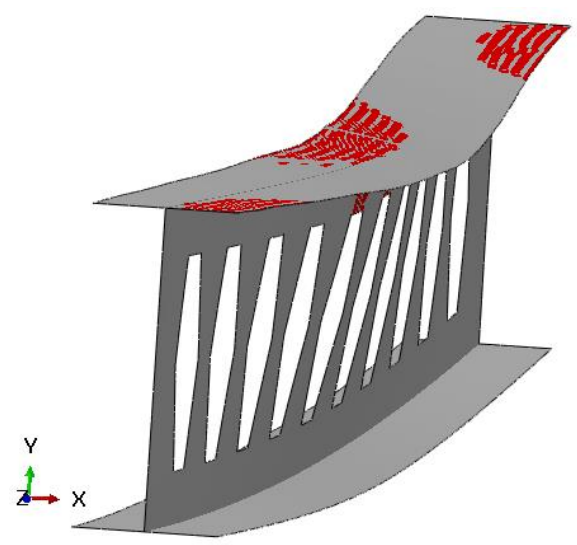

(c)

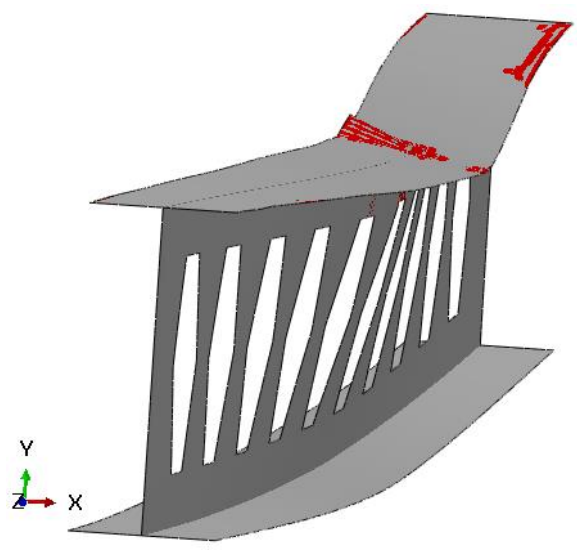

(d) 
Figura 4.4 - Evolução do modo de falha da viga do modelo 1 com imperfeição inicial IMP1. (a) Pontos notáveis do gráfico carga por deslocamento fora do plano do modelo. (b) Início da plastificação localizada. (c) Plastificação e flambagem lateral com torção. (d) Plastificação, flambagem global e corrugação da mesa comprimida.

O modelo 3 tem, para condições ideais sem imperfeições iniciais, o momento de início de plastificação maior que o momento crítico global e menor que o momento crítico local. A Figura 4.5 apresenta curva relacionando o fator de proporcionalidade de momento fletor (LPF) por deslocamento fora do plano, que é o deslocamento do ponto vermelho da seção transversal na direção $X$, para respostas da estrutura com diferentes imperfeições iniciais aplicadas. Nota-se que para este caso, há uma perda do comportamento linear para valor de LPF próximo a 0.7 , que é correspondente a flambagem lateral com torção que acontece antes da plastificação, que é o pico da curva e, em seguida, acontece o enrugamento da mesa comprimida, como mostram os pontos notáveis e as respectivas deformadas da Figura 4.6, onde (a) são os pontos notáveis do gráfico carga por deslocamento fora do plano do modelo, (b) indica o acontecimento da interação da flambagem global e plastificação e (c) apresenta o enrugamento localizado da mesa superior. De tal modo, a evolução do modo de falha do modelo 3 é caracterizado pelo início da plastificação, seguido da flambagem lateral com torção e, por fim, o enrugamento da mesa superior. 


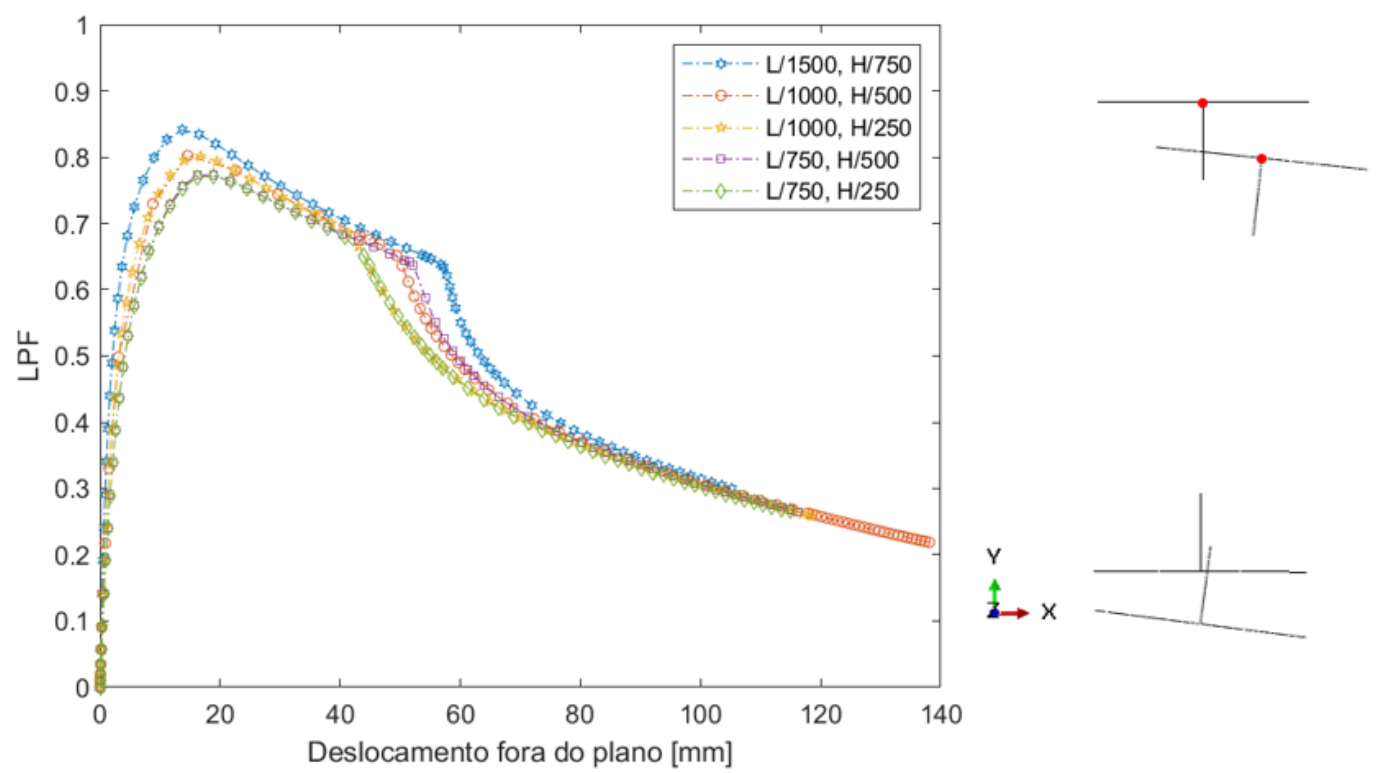

Figura 4.5 - Curva de fator de proporcionalidade do momento fletor (LPF) por deslocamento fora do plano do modelo 3.

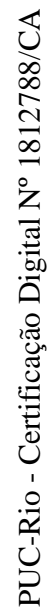

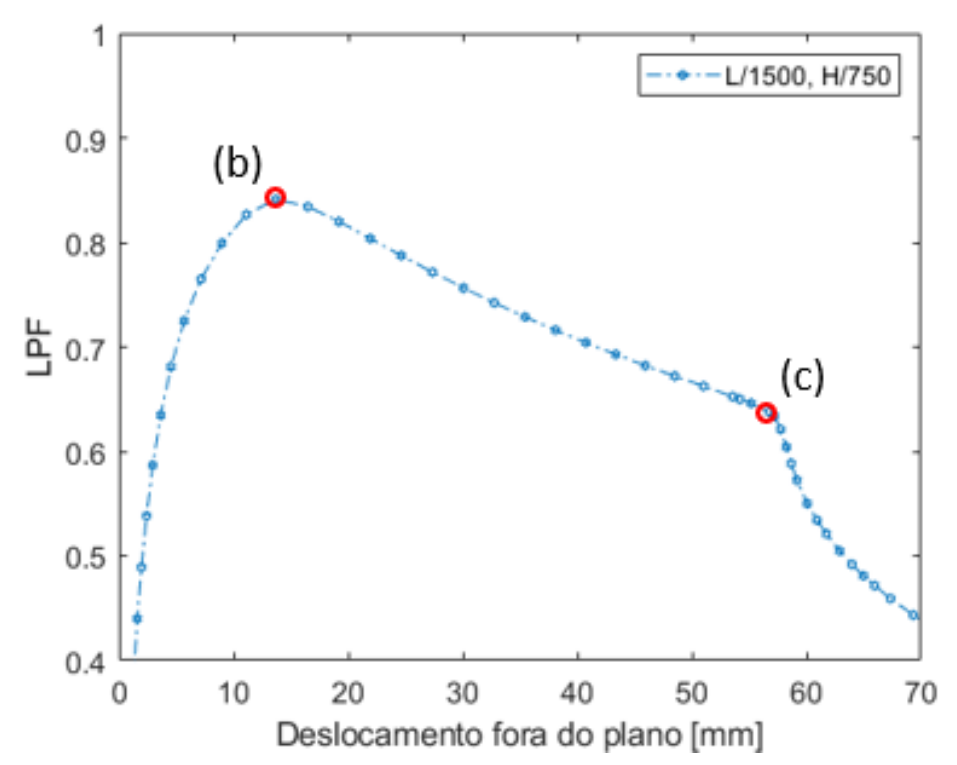

(a) 


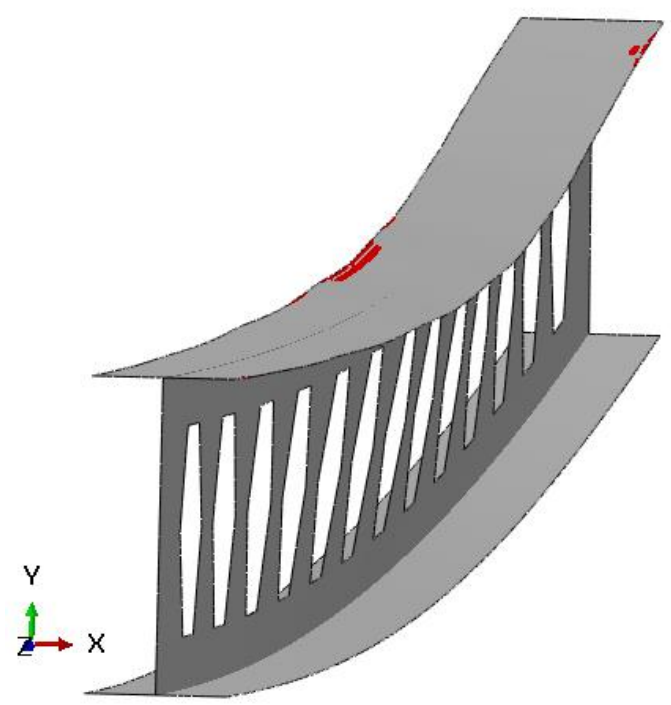

(b)

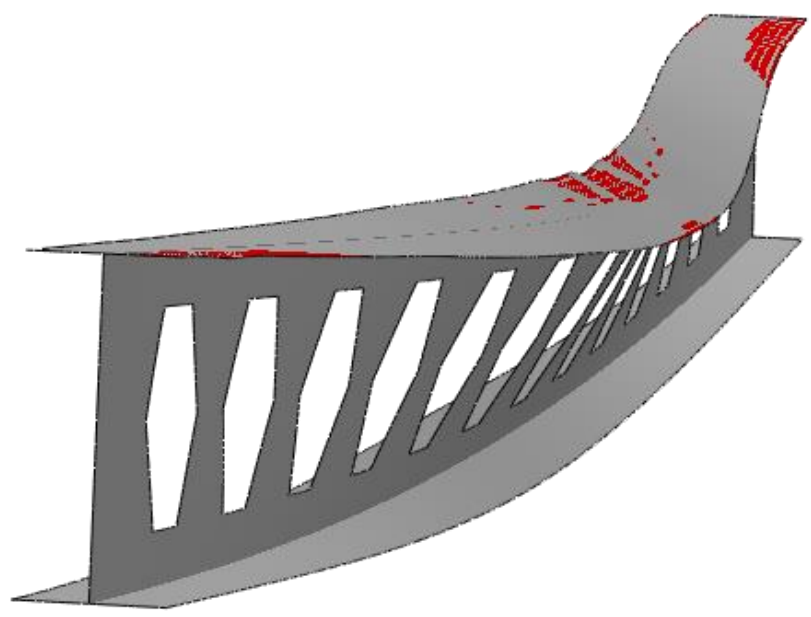

(c)

Figura 4.6 - Evolução do modo de falha da viga do modelo 3 com imperfeição inicial IMP1. (a) Pontos notáveis do gráfico carga por deslocamento fora do plano do modelo.

(b) Indica o acontecimento da interação da flambagem global e plastificação. (c)

Enrugamento localizado da mesa superior.

O modelo 5 tem, para condições ideais, sem imperfeições iniciais, o momento de início de plastificação maior que o momento crítico global e menor que o momento crítico local. A Figura 4.7 apresenta curva de fator de proporcionalidade do momento fletor (LPF) por deslocamento fora do plano, que é o deslocamento do ponto vermelho da seção transversal na direção X, para respostas da estrutura com diferentes imperfeições iniciais aplicadas, e nota-se que para este caso, há uma perda da linearidade do comportamento da estrutura para valor de LPF próximo a 0.7 , que é correspondente a flambagem lateral com torção, em seguida há o aparecimento de meias ondas na mesa comprimida e, após, acontece o início da plastificação, que é o pico da curva e, em seguida, acontece o enrugamento da mesa comprimida, como mostram os pontos notáveis e as respectivas deformadas da Figura 4.8, onde (a) são os pontos notáveis do gráfico fator de proporcionalidade do momento fletor (LPF) por deslocamento fora do plano, (b) Início da flambagem lateral com torção, perda da linearidade da resposta da estrutura, (c) aparecimento de meias ondas na mesa comprimida, caracterizando flambagem local da mesa, (d) 
início da plastificação localizada, pico da curva LPF x Deslocamento fora do plano e (e) enrugamento da mesa comprimida, ponto de perda de rigidez considerável. De tal modo, a evolução do modo de falha do modelo 5 é caracterizado pelo início da flambagem lateral com torção, seguido da flambagem local do 'tê' e do início da plastificação e, por fim, o enrugamento da mesa superior.

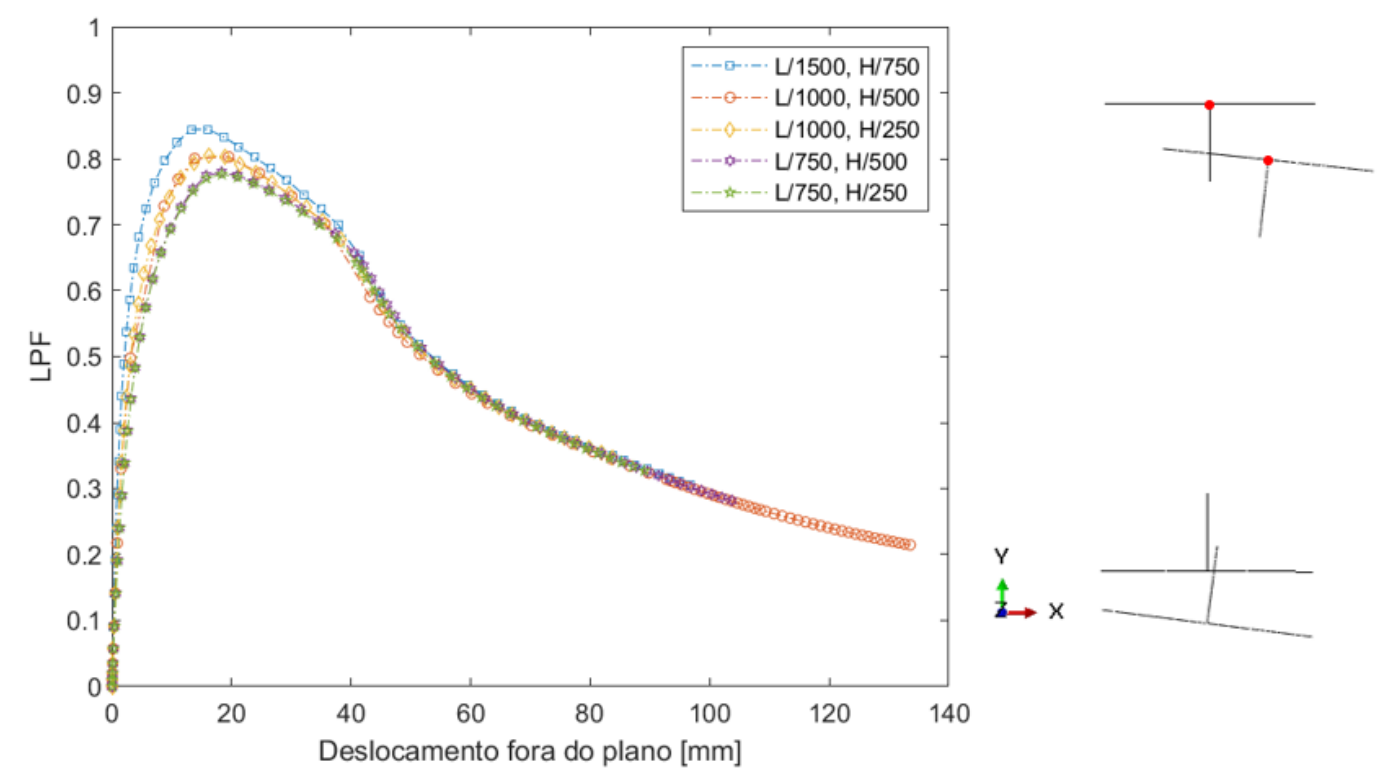

Figura 4.7 - Curva de fator de proporcionalidade do momento fletor (LPF) por deslocamento fora do plano do modelo 5

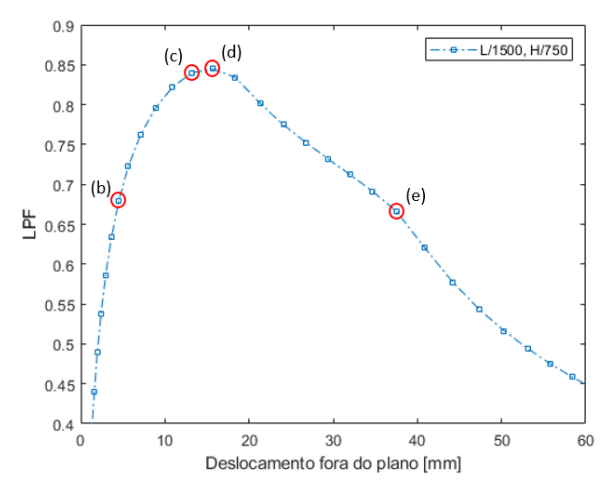

(a) 


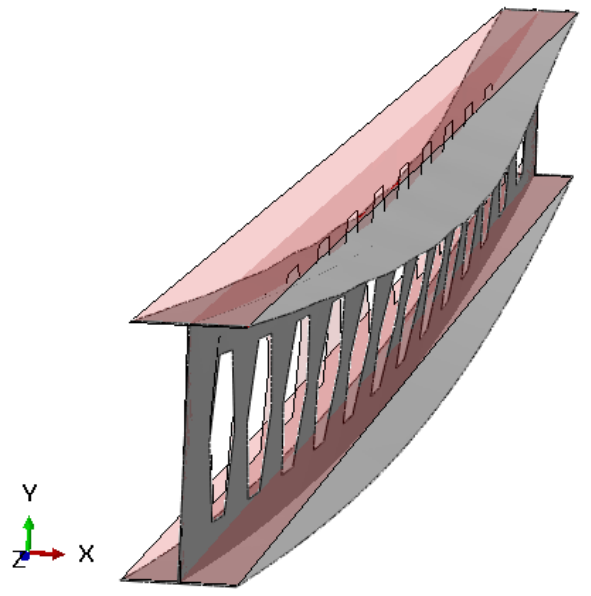

(b)

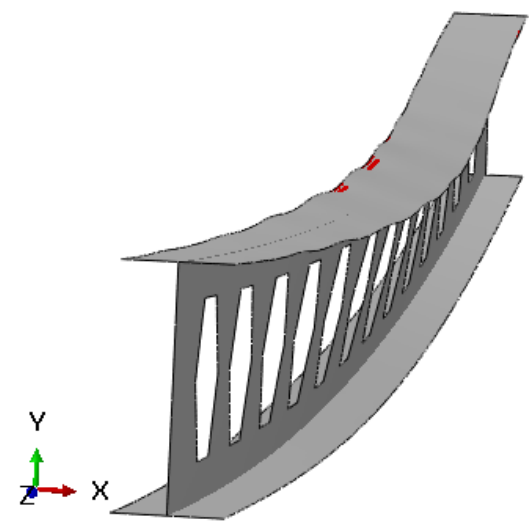

(d)

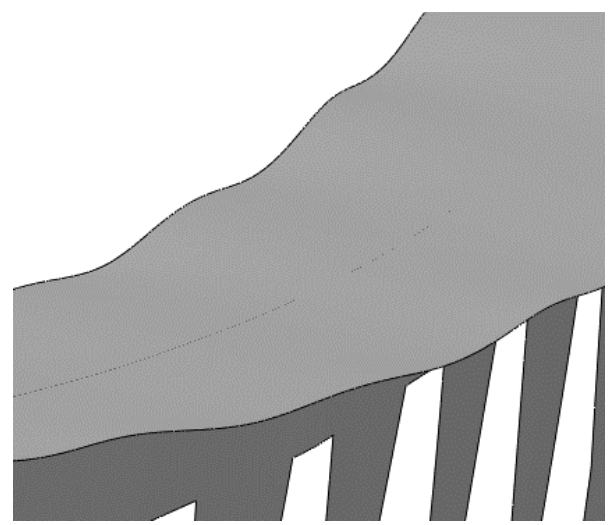

(c)

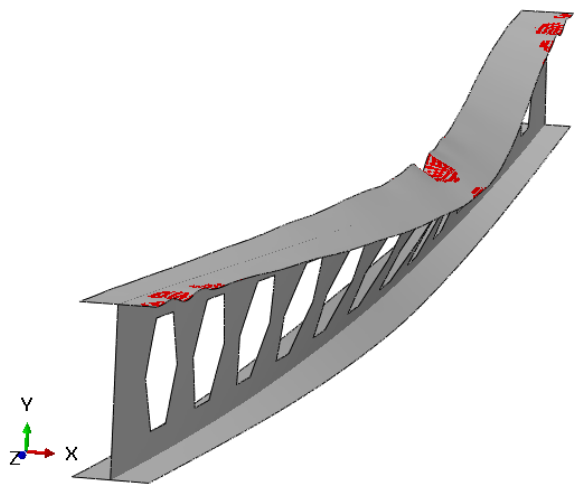

(e)

Figura 4.8 - Evolução do modo de falha da viga do modelo 5 com imperfeição inicial IMP1. (a) Pontos notáveis do gráfico fator de proporcionalidade do momento fletor (LPF) por deslocamento fora do plano; (b) Início da flambagem lateral com torção, perda da linearidade da resposta da estrutura; (c) Aparecimento de meias ondas na mesa comprimida, caracterizando flambagem local da mesa; (d) Início da plastificação localizada, pico da curva LPF x Deslocamento fora do plano; (e) Enrugamento da mesa comprimida, ponto de perda de rigidez considerável.

O modelo 6 tem momento de início de plastificação maior que os momentos críticos globais e locais, o que, para a estrutura perfeita, faz com que as flambagens local e global tendam a acontecer antes de atingir o escoamento do material. A Figura 4.9, onde (a) expõe a resposta para o modelo 6 com diferentes imperfeições iniciais e, analisando o comportamento a cada incremento, é possível observar que as flambagens 
global e local começam a aparecer pouco antes do que o início da plastificação, como mostrado na Figura 4.9 (b). O início da plastificação acontece no pico da curva de fator de proporcionalidade de carga de momento fletor (LPF) por deslocamento fora do plano, que é o deslocamento do ponto vermelho da seção transversal na direção $X$, como mostra a Figura 4.9 (c). Por fim, a Figura 4.9 (d) mostra o detalhe da flambagem da mesa comprimida que aparece no ponto (b). De tal modo, a evolução do modo de falha do modelo 6 é caracterizado pelo início da flambagem lateral com torção, seguido da flambagem local do 'tê' e do início da plastificação e, por fim, o enrugamento da mesa superior. 


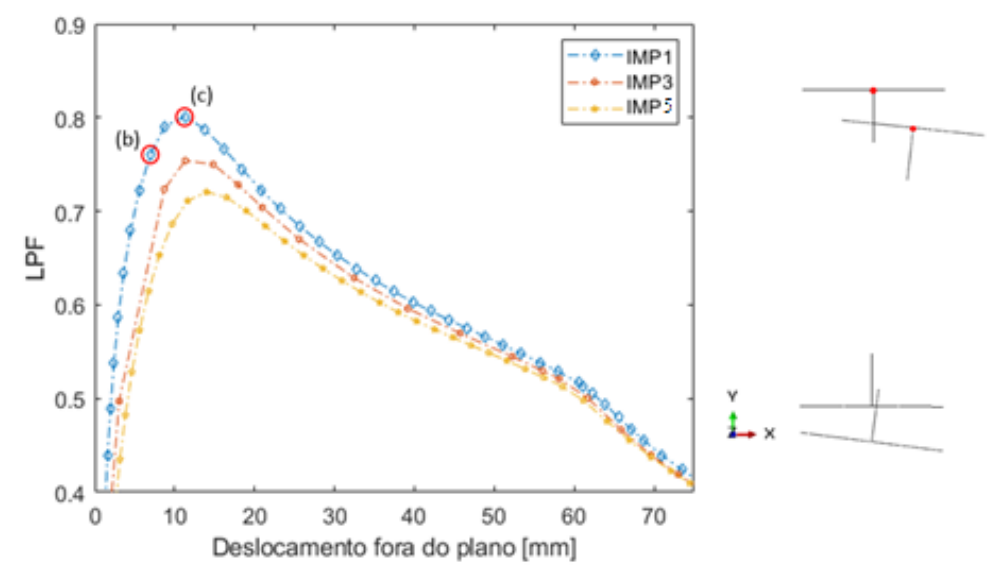

(a)

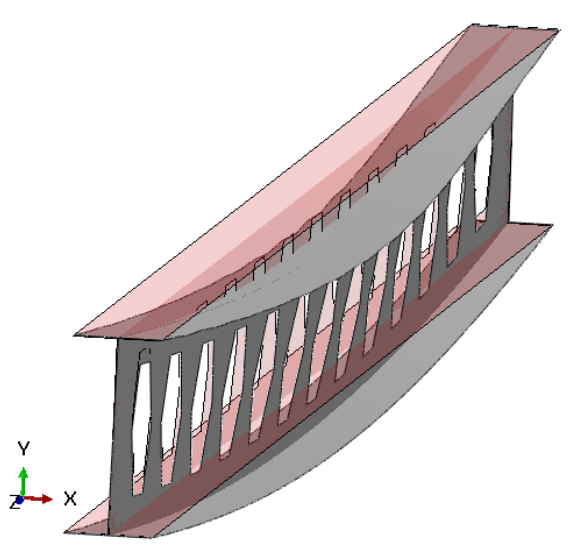

(b)

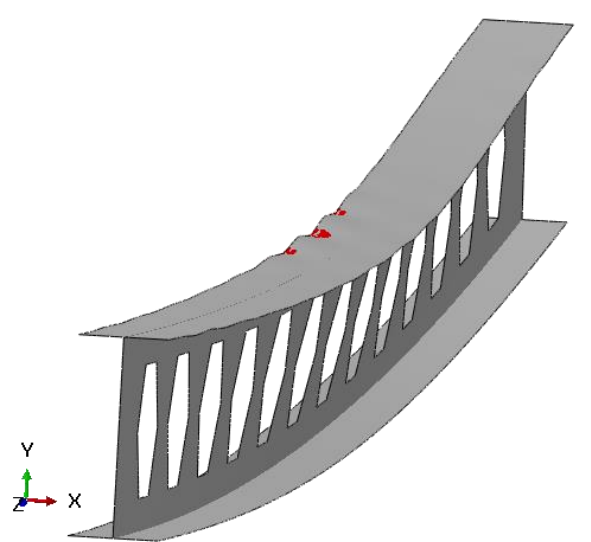

(c)

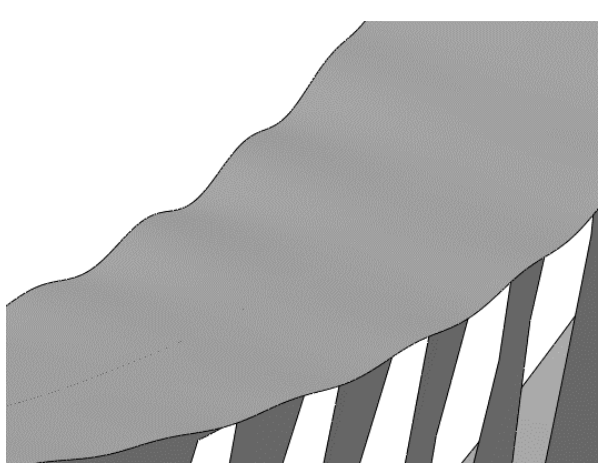

(d)

Figura 4.9 - Evolução do modo de falha da viga do modelo 6 com imperfeição inicial IMP1 (a) Curva de fator de proporcionalidade do momento fletor (LPF) por deslocamento fora do plano, direção X; (b) Deformada pré-pico da curva, mostrando ocorrência da flambagem 
lateral com torção e flambagem local da mesa; (c) Ocorrência do início da plastificação e flambagens global e local; (d) Detalhe da flambagem local da mesa do incremento (b).

Os demais modelos (2, 4 e 7) apresentam comportamento de forma semelhante aos já mostrados nesta seção.

A Tabela 4.2 apresenta os valores de momento último para cada modelo avaliado, para as respectivas imperfeições geométricas iniciais aplicadas (valores de imperfeição foram fornecidos na Tabela 3.3). Nota-se que o sistema abordado é sensível à imperfeição global, diminuindo o momento último das vigas estudadas. As imperfeições locais influenciam a capacidade de resistência pós crítica dos modelos com mesas mais espessas, onde o ponto da curva que ocorre a formação da rótula plástica devido ao enrugamento da mesa superior acontece com maiores deformações para os casos onde a imperfeição local foi menor, como o caso do modelo 1, mostrado na Figura 4.3.

Tabela 4.2 - Momentos últimos de cada modelo para as respectivas imperfeições geométricas iniciais

Momentos últimos MEF (kN.m)

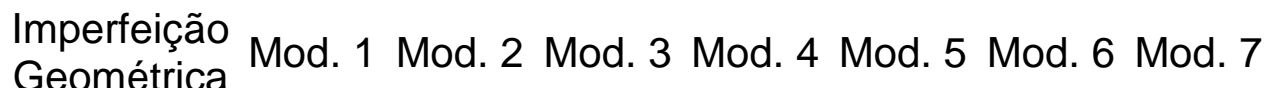

\begin{tabular}{cccccccc}
\hline IMP 1 & 79.4 & 64.0 & 56.4 & 49.2 & 44.0 & 33.0 & 43.2 \\
IMP 2 & 77.8 & 61.2 & 53.8 & 46.8 & 41.8 & 31.0 & 41.9 \\
IMP 3 & 77.5 & 61.0 & 53.7 & 46.9 & 40.9 & - & 41.8 \\
IMP 4 & 74.9 & 58.9 & 51.8 & 45.4 & 40.4 & 29.6 & 40.7 \\
IMP 5 & 74.9 & 58.8 & 51.7 & 45.3 & 39.5 & - & 40.6 \\
\hline
\end{tabular}

\section{3.}

\section{Resistência relativa}

A resistência relativa é utilizada a fim de avaliar a resistência de cada modelo e correlaciona o momento último com o momento de plastificação. Os momentos de plastificação para cada uma das seções transversais analisadas neste trabalho foram calculados utilizando os princípios de resistência dos materiais, considerando seção transversal localizada no 
meio da abertura e os momentos últimos dos modelos de elementos finitos, MuMEF, foram obtidos considerando as imperfeições iniciais IMP1. Os momentos últimos obtidos conforme o Método da Resistência Direta $\left(M_{u D S M}\right)$ e os calculados conforme o Design Guide $31\left(M_{u D G}\right)$ também estão listados na Tabela 4.3.

Tabela 4.3 - Momentos de plastificação e momentos últimos considerando IMP1

\begin{tabular}{cccc}
\hline Modelo & $\begin{array}{c}M_{u_{M E F}} \\
(k N . m)\end{array}$ & $\begin{array}{c}M_{u_{M R D}} \\
(k N . m)\end{array}$ & $\begin{array}{c}M_{u_{D G}} \\
(k N . m)\end{array}$ \\
\hline 1 & 77.9 & 76.6 & 63.4 \\
2 & 61.2 & 65.8 & 49.9 \\
3 & 53.8 & 61.4 & 44.7 \\
4 & 46.8 & 53.6 & 40.9 \\
5 & 41.7 & 47.4 & 38.2 \\
6 & 31.0 & 35.2 & 33.3 \\
7 & 41.9 & 48.0 & 37.6 \\
\hline
\end{tabular}

A partir dos momentos de plastificação, esbeltez global, esbeltez local e os momentos últimos obtidos com as diferentes abordagens presentes neste estudo, obtêm-se as resistências relativas de cada método de cálculo, como mostra a Tabela 4.4, junto com a respectiva evolução da falha de cada modelo.

Tabela 4.4 - Esbeltezes, resistências relativas e respectivos modos de falha

\begin{tabular}{ccccccc}
\hline Modelo & $\lambda_{G}$ & $\lambda_{L}$ & $\chi_{F E M}$ & $\chi_{M R D}$ & $\chi_{D G}$ & $\begin{array}{c}\text { Mecanismos de } \\
\text { falha }\end{array}$ \\
\hline 1 & 0.84 & 0.81 & 0.90 & 0.89 & 0.73 & P - FLT - EM \\
2 & 1.06 & 0.81 & 0.71 & 0.76 & 0.58 & P - FLT - EM \\
3 & 1.07 & 0.87 & 0.69 & 0.79 & 0.57 & P - FLT - EM \\
4 & 1.09 & 0.93 & 0.67 & 0.77 & 0.59 & FLT - P - FT - EM \\
5 & 1.10 & 0.99 & 0.65 & 0.74 & 0.60 & FLT - FT - P - EM \\
6 & 1.14 & 1.13 & 0.57 & 0.65 & 0.62 & FLT - FT - P - EM \\
7 & 1.34 & 0.81 & 0.48 & 0.55 & 0.43 & FLT - P - EM \\
\hline
\end{tabular}

* MEF, MRD e DG referem-se, respectivamente, a Método dos Elementos Finitos, Método da Resistência Direta e Design Guide 31. Na coluna de modos de falha, P significa plastificação, FLT significa flambagem lateral com torção, FT significa flambagem local do 'tê', EM significa enrugamento da mesa comprimida e "-" significa que o modo de falha seguinte acontece em sequência. 
A partir dos dados de resistência relativa, esbeltezes globais e locais para cada um dos modelos avaliados, é possível avaliar a influência das esbeltezes na capacidade de resistência dos elementos, para os casos com combinação de imperfeições iniciais IMP1. É possível notar na Figura 4.10 que a resistência relativa decresce para todos os modelos de elementos finitos avaliados conforme as esbeltezes aumentam. Na Figura 4.11 estão pontuadas as resistências relativas calculadas conforme o método da resistência direta e é possível notar que, conforme a esbeltez global aumenta, as capacidades de resistência diminuem, mas à medida que a esbeltez local aumenta, algumas geometrias apresentam aumento do momento último resistente. A Figura 4.12 apresenta as resistências relativas calculadas de acordo com o guia de dimensionamento norte americano Design Guide e, ao passo que a esbeltez global aumenta, a resistência diminui, no entanto, há uma variação do comportamento da capacidade de resistência enquanto a esbeltez local aumenta. Portanto, é possível notar que para o cálculo segundo o MEF, as esbeltezes global e local influenciam diretamente na diminuição da resistência relativa, contudo, para os MRD e o DG os valores de resistência relativa se alternam.

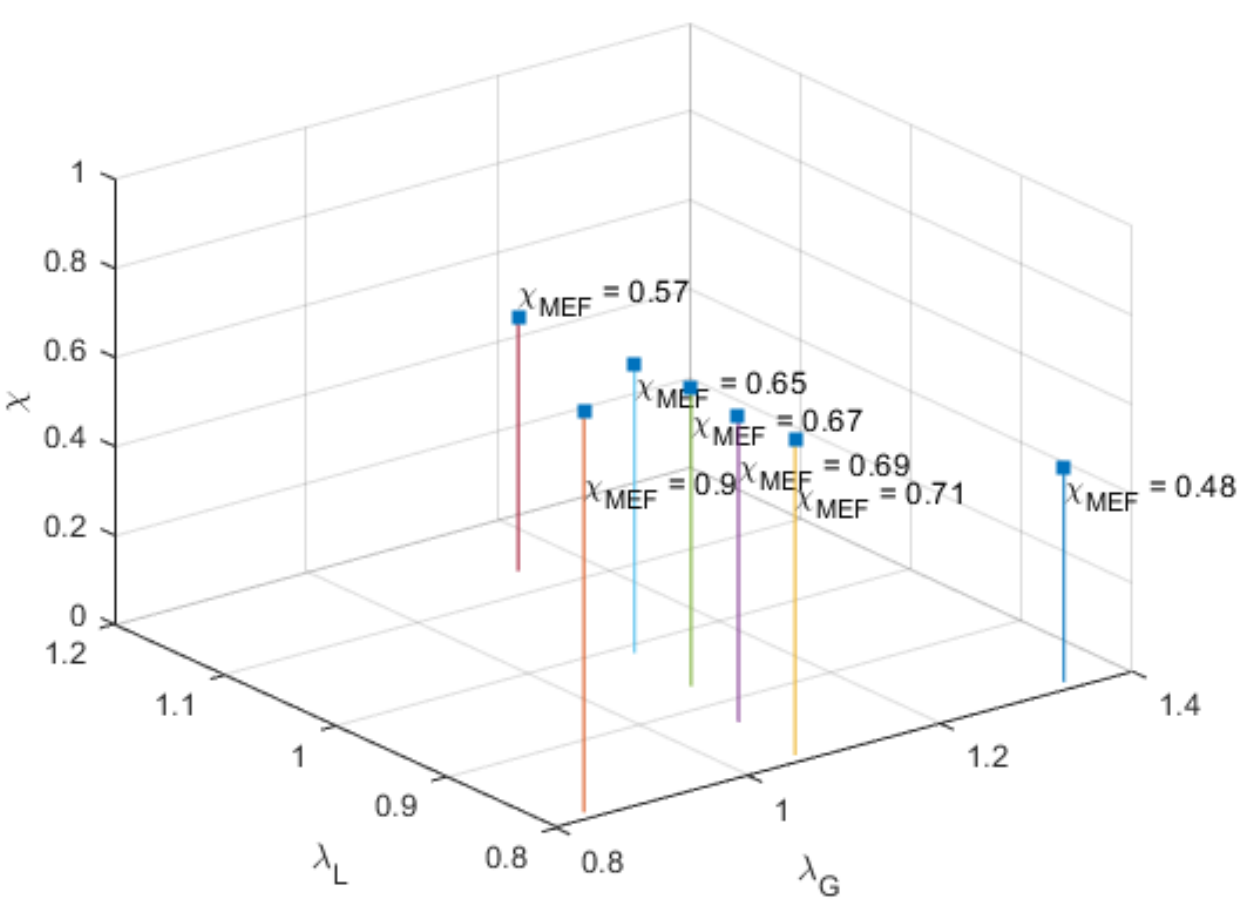


Figura 4.10 - Gráfico $\chi \times \lambda_{G} \times \lambda_{L}$ para resistência relativas pelo método dos elementos finitos

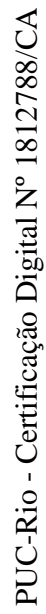

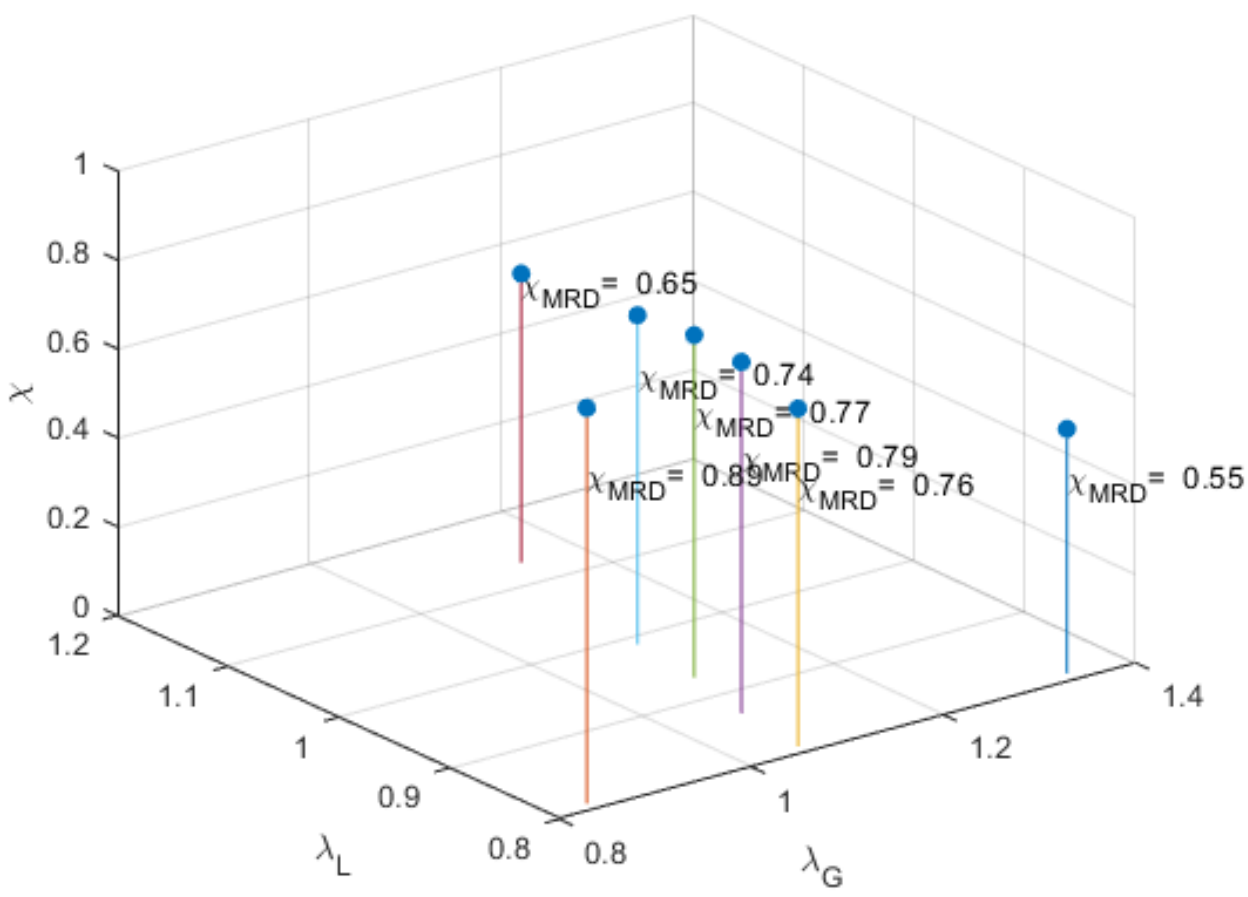

Figura 4.11 - Gráfico $\chi \times \lambda_{G} \times \lambda_{L}$ para resistência relativas pelo Método da Resistência Direta

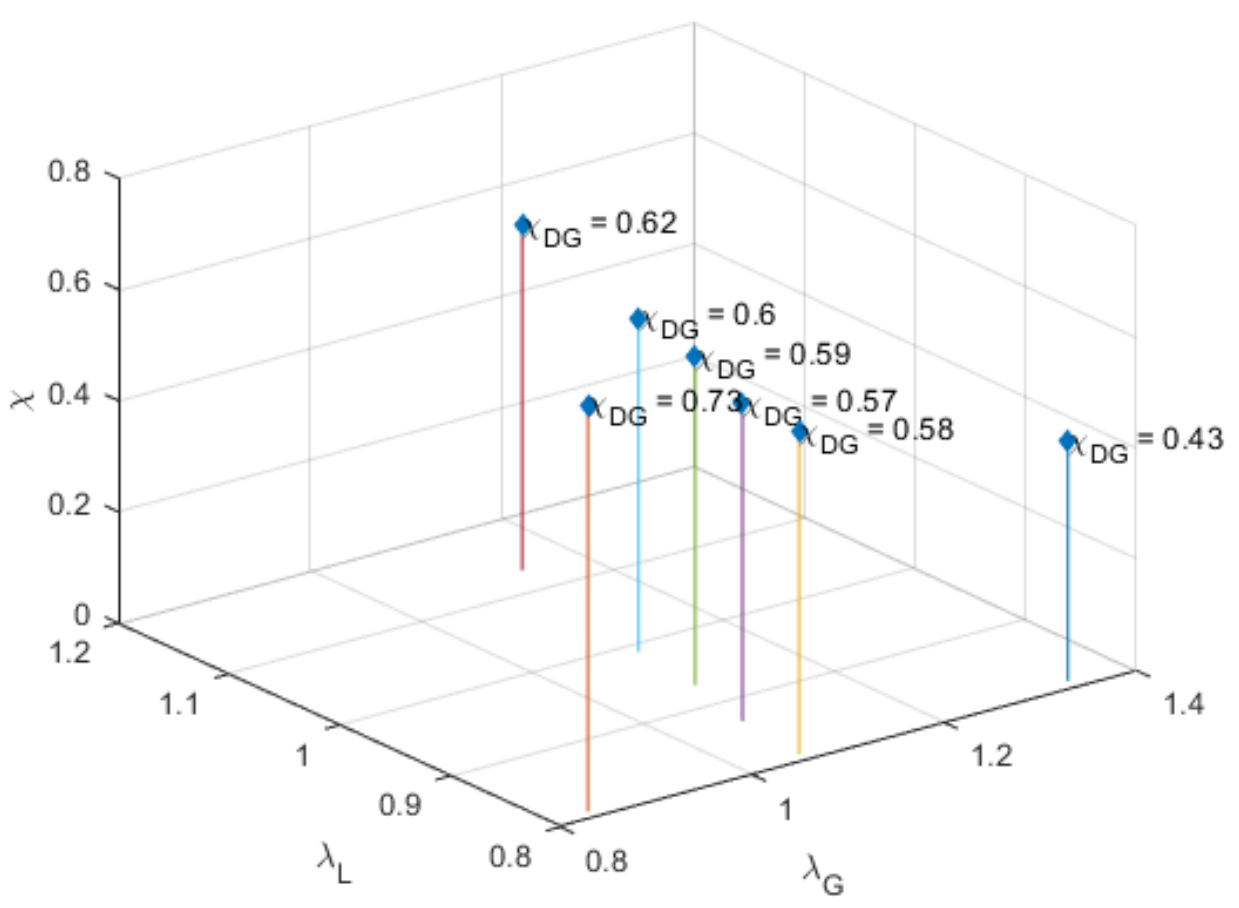


Figura 4.12 - Gráfico $\chi \times \lambda_{G} \times \lambda_{L}$ para resistência relativas pelo Design Guide 31

Enfim, com o intuito de comparar as resistências relativas obtidas através de cada um dos métodos de cálculo abordados neste trabalho, a Figura 4.13 faz a comparação relacionando a resistência relativa, $\chi$, e a esbeltez global, $\lambda_{G}$, com a esbeltez local, $\lambda_{L}$, fixada em 0.81 , uma vez que há modelos com mesma esbeltez local e diferentes esbeltezes locais. Além disso, apresenta também para comparação a curva de resistência para vigas ideais. Notase que o Design Guide apresenta capacidade de resistência menor do que os outros métodos de cálculo para as geometrias apresentadas, subestimando a resistência destes elementos, enquanto o método da resistência direta superestimou as resistências dos elementos avaliados, com exceção do caso em que a plastificação foi o modo de falha dominante. Observa-se ainda que todas as resistências calculadas apresentam valores abaixo da curva de resistência para vigas ideais.

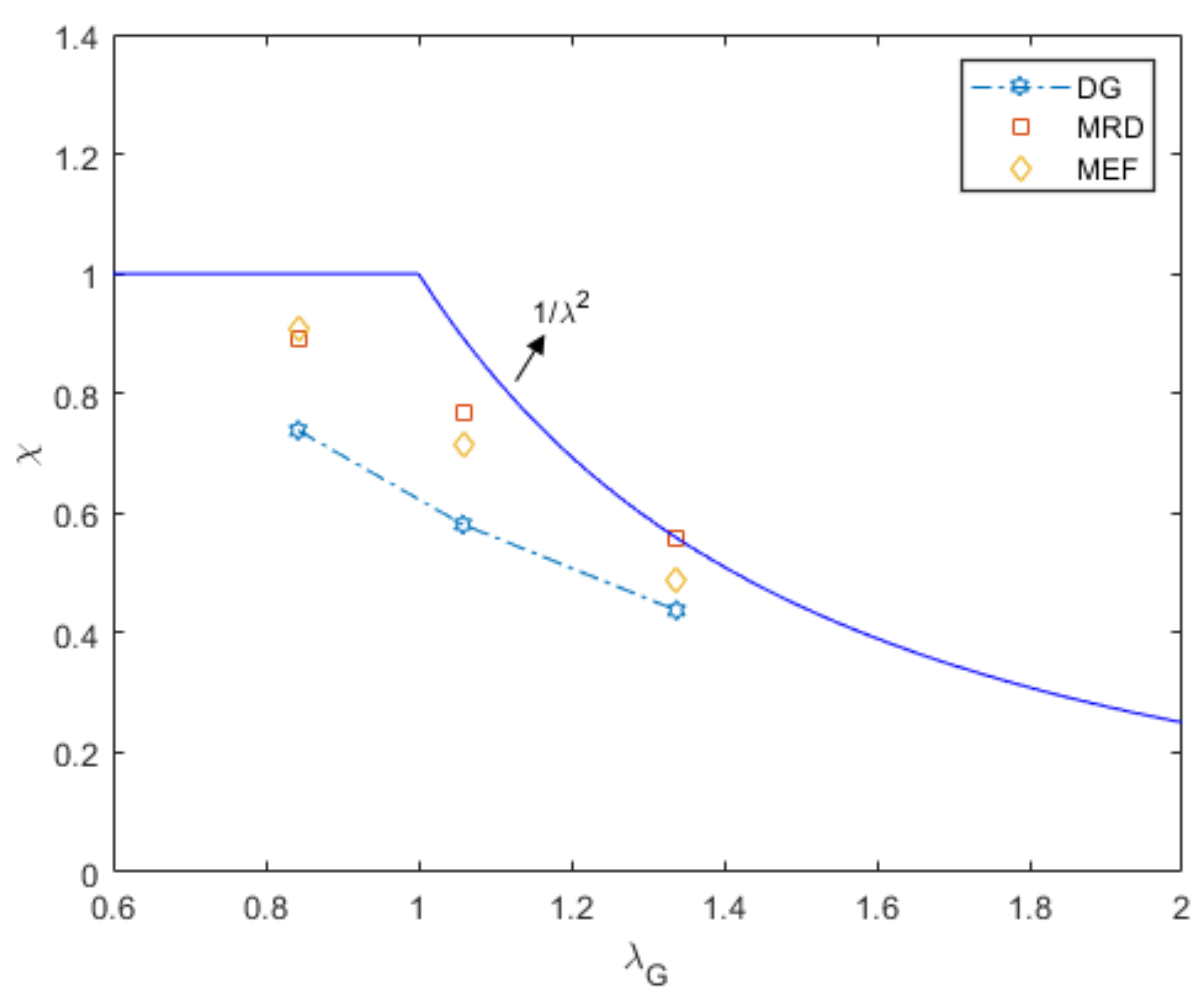

Figura 4.13 - Comparativo resistências relativas MEF, MRD e DG 


\section{5 \\ Conclusões e sugestões para pesquisas futuras}

\section{1 .}

\section{Conclusões}

O objetivo desta pesquisa foi investigar a interação entre os modos de flambagem global (flambagem lateral com torção) e local (flambagem local do 'tê') e sua influência na diminuição da capacidade de resistência de vigas casteladas padrão Litzka biapoiadas e sob condição de flexão pura. Com o objetivo de avaliar estes tópicos, um estudo paramétrico utilizando o método dos elementos finitos para análises lineares de flambagem e análises não-lineares com imperfeições iniciais e imperfeição do material foi elaborado e validado para obter as respostas de momentos críticos e últimos. O método da resistência direta foi empregado, sem passar por calibração para vigas casteladas, para calcular os momentos resistentes nominais de cada seção transversal adotada. As diretrizes para o dimensionamento de vigas casteladas e celulares segundo o Design Guide 31 foram seguidas para cálculo dos momentos resistentes, mas abordam os estados limites de flambagem global e local em seções separadas e não menciona efeito da interação entre estes. Por fim, comparou-se os momentos resistentes obtidos com por elementos finitos com os de cada um dos métodos de dimensionamento. As principais conclusões deste trabalho são:

- O método da resistência direta superestima as resistências últimas para todos os modelos avaliados neste trabalho, com exceção do modelo 1, que teve a plastificação como modo de falha dominante;

- O Design Guide 31 subestima as resistências para todas as configurações testadas, ainda que não seja considerada a interação entre os modos de flambagem;

- As geometrias analisadas neste estudo se mostraram sensíveis às imperfeições iniciais referentes ao modo de flambagem global, 
apresentando momentos últimos resistentes menores conforme o grau de imperfeição aumenta;

- As imperfeições referentes ao modo de flambagem local da mesa tem influência na capacidade de resistência pós-crítica, mas não alteraram consideravelmente os momentos últimos resistentes das geometrias analisadas.

\section{2.}

\section{Sugestões para pesquisas futuras}

Há ainda uma série de lacunas dentro do assunto de vigas casteladas que devem ser estudadas. Algumas sugestões para pesquisas futuras são:

- Estender o estudo com modelos constitutivos considerando o encruamento do aço;

- Testar experimentalmente a interação entre os modos de flambagem global e local para vigas casteladas sem travamento fora do plano;

- Estender os estudos com o Método da Resistência Direta para prever o comportamento das seções transversais presentes neste estudo;

- Avaliar a capacidade de resistência pós-flambagem dos sistemas estudados neste trabalho;

- Estender o estudo das interações entre modos de flambagem em vigas casteladas. 


\section{6 Referências bibliográficas}

[1] Barrett, N. 50 Years Ago: Contemporary Factory Design - some notable examples, 2010. Disponível em: https://www.newsteelconstruction.com/wp/contemporary-factory-designsome-notable-examples/. Acesso em: 29 de novembro de 2019.

[2] Sameer S. Fares, J. Coulson, and David W. Dinehart, "Castellated and Cellular Beam Design 31," Am. Inst. Steel Constr., 2016

[3] AISI, "North American Specification for the Design of Cold-Formed Steel Structural Members," 2007.

[4] Koiter, W. T., Over de stabiliteit van her elastisch evenwicht. PhD Thesis, H.J. Paris, Amsterdam, The Netherlands, 1945. English translation as NASDA TTF-10,833, 1957 and AFFDL Report TR 70-25, 1970 (in Dutch).

[5] BUDIANSKY, Bernard. Theory of buckling and post-buckling behavior of elastic structures. In: Advances in applied mechanics. Elsevier, 1974. p. 1-65.

[6] THOMPSON, J. M. T. Basic principles in the general theory of elastic stability. Journal of the Mechanics and Physics of Solids, v. 11, n. 1, p. 13-20, 1963.

[7] CHILVER, A. H. Coupled modes of elastic buckling. Journal of the Mechanics and Physics of Solids, v. 15, n. 1, p. 15-28, 1967.

[8] JOHNS, Kenneth C. Simultaneous buckling in symmetric structural systems. Journal of the Engineering Mechanics Division, v. 98, n. 4, p. 835-848, 1972.

[9] JOHNS, Kenneth C. Imperfection sensitivity of coincident buckling systems. International Journal of Non-Linear Mechanics, v. 9, n. 1, p. 121, 1974.

[10] JOHNS, K. C. Some statistical aspects of coupled buckling structures. In: Buckling of Structures. Springer, Berlin, Heidelberg, 1976. p. 199-207. 
[11] JOHNS, K. C.; CHILVER, A. H. Multiple path generation at coincident branching points. International Journal of Mechanical Sciences, v. 13, n. 11, p. 899-910, 1971.

[12] SUPPLE, W. J. On the change in buckle pattern in elastic structures. International Journal of Mechanical Sciences, v. 10, n. 9, p. 737-745, 1968.

[13] SUPPLE, W. J. On the change in buckle pattern in elastic structures. International Journal of Mechanical Sciences, v. 10, n. 9, p. 737-745, 1968.

[14] SUPPLE, W. J. Initial post-buckling behaviour of a class of elastic structural systems. International Journal of Non-Linear Mechanics, v. 4, n. 1, p. 23-36, 1969.

[15] HO, D. The influence of imperfections on systems with coincident buckling loads. International Journal of Non-Linear Mechanics, v. 7, n. 3, p. 311-321, 1972.

[16] HO, D. U. E. N. Buckling load of non-linear systems with multiple eigenvalues. International Journal of Solids and Structures, v. 10, n. 11, p. 1315-1330, 1974.

[17] THOMPSON, J. M. T.; GÁSPÁR, Zs. A buckling model for the set of umbilic catastrophes. In: Mathematical Proceedings of the Cambridge Philosophical Society. Cambridge University Press, 1977. p. 497-507.

[18] THOMPSON, John MT; HUNT, Giles W. A theory for the numerical analysis of compound branching. Zeitschrift für angewandte Mathematik und Physik ZAMP, v. 22, n. 6, p. 1001-1015, 1971.

[19] Bijlaard, P. P.; Fisher, G. P. Interaction of column and local buckling in compression members. National Advisory Committee for Aeronautics, 1952.

[20] Bijlaard, Paul P.; Fisher, G. O. Column strength of H-sections and square tubes in postbuckling range of component plates. Cornell Univ., 1953.

[21] Van der Neut, A., The interaction of local buckling and column failure of thin-walled compression members. 12th Int. Cong, r. ot Applied Mechanics, Stanford. Springer Verlag, Berlin, 1969, 38999. 
[22] VAN DER NEUT, A. The sensitivity of thin-walled compression members to column axis imperfection. International Journal of Solids and Structures, v. 9, n. 8, p. 999-1011, 1973.

[23] SCHAFER, Benjamin W.; PEKOZ, Teoman. Direct strength prediction of cold-formed steel members using numerical elastic buckling solutions. 1998.

[24] HANCOCK, Gregory J.; KWON, Young B.; BERNARD, E. Stefan. Strength design curves for thin-walled sections undergoing distortional buckling. Journal of Constructional Steel Research, v. 31, n. 2-3, p. 169186, 1994.

[25] TRAHAIR, Nicholas Snowden. Flexural-torsional buckling of structures. Routledge, 2017.

[26] SCHAFER, Benjamin W. The direct strength method of cold-formed steel member design. Journal of constructional steel research, v. $64, \mathrm{n}$. 7-8, p. 766-778, 2008.

[27] SCHAFER, B. W. Advances in the Direct Strength Method of thinwalled steel design. In: Proceedings of the Eighth International Conference on Thin-walled Structures. Lisbon, Portugal. 2018.

[28] BIAN, Guanbo et al. Torsion of cold-formed steel lipped channels dominated by warping response. Thin-Walled Structures, v. 98, p. 565577, 2016.

[29] CAMOTIM, D.; DINIS, P. B.; MARTINS, A. D. Direct strength methoda general approach for the design of cold-formed steel structures. In: Recent trends in cold-formed steel construction. Woodhead Publishing, 2016. p. 69-105.

[30] LANDESMANN, Alexandre; CAMOTIM, Dinar; SILVA, Fernanda CM. DSM design of cold-formed steel columns failing in distortional modes at elevated temperatures. International Journal of Steel Structures, p. 1-19, 2019.

[31] AISI (American Iron and Steel Institute). 2016. North American specification for the design of cold-formed steel structural members.Washington, DC: AISI.

[32] CAMOTIM, D.; DINIS, P. B.; MARTINS, A. D. Direct strength methoda general approach for the design of cold-formed steel structures. In: 
Recent trends in cold-formed steel construction. Woodhead Publishing, 2016. p. 69-105.

[33] TORABIAN, Shahabeddin; SCHAFER, Benjamin W. Development and Experimental Validation of the Direct Strength Method for Cold-Formed Steel Beam-Columns. Journal of Structural Engineering, v. 144, n. 10, p. 04018175, 2018.

[34] B. Schafer, "Direct Strength Method (DSM) Design Guide," Des. Guid. CF06-1, Am. Iron Steel Inst., 2006.

[35] AISI, "North American Specification for the Design of Cold-Formed Steel Structural Members," 2007.

[36] AISC, "ANSI / AISC 360-16, Specification for Structural Steel Buildings," Am. Inst. Steel Constr., p. 676, 2016.

[37] ESDEP course, Može, P., acessado em: 15/10/2019, http://fggweb.fgg.unilj.si/ /pmoze/esdep/master/toc.htm [38] ACB ${ }^{\circledR}$ and Angelina TM beams, 2016. ArcelorMittal.

[39] GRÜNBAUER BV, Diemen - Nederland. Disponível em: $<$ http://www.grunbauer.nl/eng/raatvorm.htm>. Acesso em: 10 dez. 2018. [40] Boyer, J. P. Castellated beams-new developments. AISC Engineering Journal, v. 1, n. 3, p. 104, 1964.

[41] Kerdal, D. and Nethercot, D.A. (1983). "Buckling of Laterally Unsupported Castellated Beams" Structural Stability Research Council Proceedings, 3rdlnternational Colloquium, Stability of Metal Structures, Conference Code:03354, pp 151-171.

[42] KERDAL, D.; NETHERCOT, D. A. Failure modes for castellated beams. Journal of Constructional Steel Research, v. 4, n. 4, p. 295-315, 1984. [43] ZAAROUR, Walid; REDWOOD, Richard. Web buckling in thin webbed castellated beams. Journal of Structural Engineering, v. 122, n. 8, p. 860866, 1996.

[44] REDWOOD, Richard; DEMIRDJIAN, Sevak. Castellated beam web buckling in shear. Journal of Structural Engineering, v. 124, n. 10, p. 1202-1207, 1998.

[45] CHUNG, K. F.; LIU, T. C. H.; KO, A. C. H. Investigation on Vierendeel mechanism in steel beams with circular web openings. Journal of Constructional Steel Research, v. 57, n. 5, p. 467-490, 2001. 
[46] REDWOOD, Richard; CHO, Soon Ho. Design of steel and composite beams with web openings. Journal of Constructional Steel Research, v. 25, n. 1-2, p. 23-41, 1993.

[47] RASMUSSEN, Kim JR; HANCOCK, Gregory J. Plate slenderness limits for high strength steel sections. Journal of Constructional Steel Research, v. 23, n. 1-3, p. 73-96, 1992.

[48] SWEEDAN, Amr MI. Elastic lateral stability of I-shaped cellular steel beams. Journal of Constructional Steel Research, v. 67, n. 2, p. 151163, 2011.

[49] SONCK, Delphine. Global buckling of castellated and cellular steel beams and columns. Structural Engineering International, v. 24, n. 4, p. 575-575, 2014.

[50] PANEDPOJAMAN, Pattamad; SAE-LONG, Worathep; CHUBUPPAKARN, Tanan. Cellular beam design for resistance to inelastic lateraltorsional buckling. Thin-Walled Structures, v. 99, p. 182-194, 2016.

[51] BOISSONNADE, Nicolas et al. Design of cellular beams against lateral torsional buckling. Proceedings of the Institution of Civil EngineersStructures and Buildings, v. 167, n. 7, p. 436-444, 2014.

[52] SONCK, Delphine; BELIS, Jan. Lateral-torsional buckling resistance of cellular beams. Journal of Constructional Steel Research, v. 105, p. 119128, 2015.

[53] TARAS, Andreas; GREINER, Richard. New design curves for lateraltorsional buckling-Proposal based on a consistent derivation. Journal of Constructional Steel Research, v. 66, n. 5, p. 648-663, 2010.

[54] KERDAL, D.; NETHERCOT, D. A. Failure modes for castellated beams. Journal of Constructional Steel Research, v. 4, n. 4, p. 295-315, 1984. [55] SOLTANI, M. R.; BOUCHAÏR, A.; MIMOUNE, M. Nonlinear FE analysis of the ultimate behavior of steel castellated beams. Journal of Constructional Steel Research, v. 70, p. 101-114, 2012.

[56] DE OLIVEIRA, Julia Pithan; CARDOSO, Daniel Carlos Taissum; SOTELINO, Elisa Dominguez. Elastic flexural local buckling of Litzka castellated beams: Explicit equations and FE parametric study. Engineering Structures, v. 186, p. 436-445, 2019. 
[57] ELLOBODY, Ehab. Interaction of buckling modes in castellated steel beams. Journal of Constructional Steel Research, v. 67, n. 5, p. 814825, 2011.

[58] ELLOBODY, Ehab. Nonlinear analysis of cellular steel beams under combined buckling modes. Thin-Walled Structures, v. 52, p. 66-79, 2012. [59] ABAQUS (2012) FEA computer software, Version 6.12, Product of Dassault Systemes Simulia Corp., Providence, RI, USA [60] Linhares, D. A., 2018.Mapping of Failure Modes and Resistance of Castellated Beams under Flexure 


\section{Anexos}

Anexo A

\begin{tabular}{|c|c|c|c|c|c|c|}
\hline & \multirow[b]{2}{*}{ 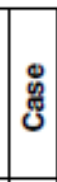 } & \multirow[b]{2}{*}{$\begin{array}{l}\text { Description of } \\
\text { Element }\end{array}$} & \multirow[b]{2}{*}{$\begin{array}{c}\text { Width-to- } \\
\text { Thickness } \\
\text { Ratio }\end{array}$} & \multicolumn{2}{|c|}{$\begin{array}{c}\text { Limiting } \\
\text { Width-to-Thickness Ratio }\end{array}$} & \multirow[b]{2}{*}{ Examples } \\
\hline & & & & $\begin{array}{cc}\lambda_{p} \\
\text { (compact/ } \\
\text { noncompact) }\end{array}$ & $\begin{array}{c}\lambda_{r} \\
\text { (noncompact/ } \\
\text { slender) }\end{array}$ & \\
\hline \multirow{5}{*}{ 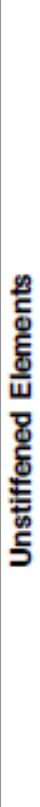 } & 10 & $\begin{array}{l}\text { Flanges of rolled } \\
\text { I-shaped sections, } \\
\text { channels, and } \\
\text { tees }\end{array}$ & $b / t$ & $0.38 \sqrt{\frac{E}{F_{y}}}$ & $1.0 \sqrt{\frac{E}{F_{y}}}$ & ${ }_{\infty}^{\frac{1 b}{1}} \frac{1}{1} t$ \\
\hline & 11 & $\begin{array}{l}\text { Flanges of } \\
\text { doubly and } \\
\text { singly symmetric } \\
\text { I-shaped built-up } \\
\text { sections }\end{array}$ & $b / t$ & $0.38 \sqrt{\frac{E}{F_{y}}}$ & $\begin{array}{l}\text { [a] [b] } \\
0.95 \sqrt{\frac{k_{c} E}{F_{L}}}\end{array}$ & ${ }_{\infty}^{\frac{b}{n}} t$ \\
\hline & 12 & $\begin{array}{l}\text { Legs of single } \\
\text { angles }\end{array}$ & $b / t$ & $0.54 \sqrt{\frac{E}{F_{y}}}$ & $0.91 \sqrt{\frac{E}{F_{y}}}$ & $\frac{b}{1} t$ \\
\hline & 13 & $\begin{array}{l}\text { Flanges of all } \\
\text { l-shaped sections } \\
\text { and channels in } \\
\text { flexure about the } \\
\text { minor axis }\end{array}$ & $b / t$ & $0.38 \sqrt{\frac{E}{F_{y}}}$ & $1.0 \sqrt{\frac{E}{F_{y}}}$ & $a_{-1}^{t} b$ \\
\hline & 14 & Stems of tees & $d t$ & $0.84 \sqrt{\frac{E}{F_{y}}}$ & $1.52 \sqrt{\frac{E}{F_{y}}}$ & 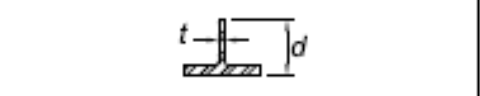 \\
\hline
\end{tabular}

